\section{Pacific Northwest}

National Laboratory

Operated by Battelle for the

U.S. Department of Energy

\title{
A Strategy to Assess Performance of Selected Low-Activity Waste Forms in an Integrated Disposal Facility
}
B. McGrail
D. Bacon
R. Serne
E. Pierce

August 2003

Prepared for the U.S. Department of Energy under Contract DE-AC06-76RL01830 


\title{
DISCLAIMER
}

This report was prepared as an account of work sponsored by an agency of the United States Government. Neither the United States Government nor any agency thereof, nor Battelle Memorial Institute, nor any of their employees, makes any warranty, express or implied, or assumes any legal liability or responsibility for the accuracy, completeness, or usefulness of any information, apparatus, product, or process disclosed, or represents that its use would not infringe privately owned rights. Reference herein to any specific commercial product, process, or service by trade name, trademark, manufacturer, or otherwise does not necessarily constitute or imply its endorsement, recommendation, or favoring by the United States Government or any agency thereof, or Battelle Memorial Institute. The views and opinions of authors expressed herein do not necessarily state or reflect those of the United States Government or any agency thereof.

\author{
PACIFIC NORTHWEST NATIONAL LABORATORY \\ operated by \\ BATTELLE \\ for the \\ UNITED STATES DEPARTMENT OF ENERGY \\ under Contract DE-AC06-76RL01830
}

Ty 


\section{Summary}

Low-activity tank wastes will be generated during cleanup of high-level radioactive tank wastes on the Hanford site. The low-activity tank waste will be among the largest volumes of radioactive waste within the U.S. Department of Energy (DOE) complex and is one of the largest inventories of long-lived radionuclides planned for disposal in a low-level waste facility. The Department of Energy's Office of River Protection is evaluating several options for immobilization of low-activity tank wastes for eventual disposal in a shallow subsurface facility at the Hanford Site. A significant portion of the waste will be converted into low-activity waste (LAW) glass with a conventional Joule-heated ceramic melter. In addition, three supplemental treatment processes are presently under consideration by the DOE to treat wastes in selected tanks with the goal of accelerating the overall cleanup mission at the Hanford site. These are: 1) bulk vitrification (BV), 2) cementation or the cast stone (CS) process, and 3) steam reformation (SR). The DOE is expected to select by October 2003 one or more of these supplemental treatment technologies for more detailed evaluation. As part of the selection process, a preliminary risk assessment is being performed to evaluate the impacts of the disposal facility on public health and environmental resources.

The same computational framework used to conduct the 2001 ILAW performance assessment will be used for all three waste forms. Cast stone will be modeled with a diffusion-advection transport model and bulk vitrified glass and steam reformed LAW will be modeled with a reactive chemical transport simulator. Modeling waste form performance requires the determination of a number of wasteform specific input parameters. The required input parameters for BV and SR waste forms are derived from a mechanistic model that describes the effect of solution chemistry on contaminant release rates. The single-pass flow-through test is the principal method used to obtain these input parameters, supplemented by product consistency test measurements and physical property measurements. The diffusiveadvective transport model for cast stone requires measurements of effective diffusion coefficients and hydraulic properties. 


\section{Glossary}

ASTM American Society for Testing and Materials

BV bulk vitrification

CS cast stone

DOE U.S. Department of Energy

EMSP Environmental Management Science Program

HLW high-level waste

ICP-OES inductively coupled plasma optical emission spectroscopy

ICP-MS inductively coupled plasma mass spectrometry

ILAW immobilized low-activity waste

ISO International Standards Organization

LAW low-activity waste

PCT product consistency test

PNNL Pacific Northwest National Laboratory

PUF pressurized unsaturated flow

RH relative humidity

SEM Scanning Electron Microscopy

SPFT single-pass flow-through

SR steam reformer

STORM Subsurface Transport Over Reactive Multiphases

S/V surface area-to-solution volume ratio

VHT vapor hydration test

XRD X-ray diffraction

XRF X-ray fluorescence 


\section{Contents}

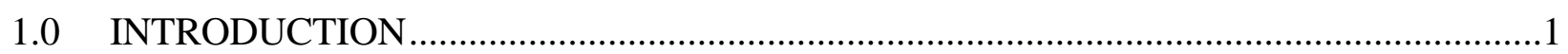

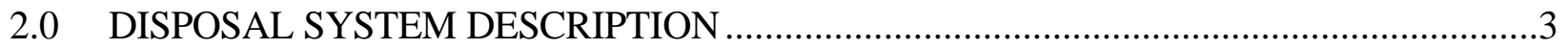

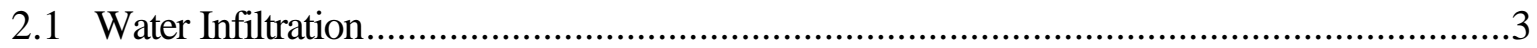

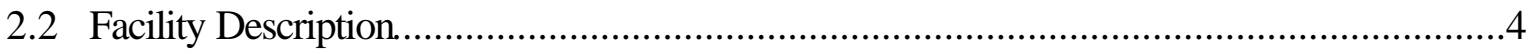

2.3 Waste Package Descriptions .....................................................................................

2.3.1 Waste Treatment Plant Glass ...........................................................................

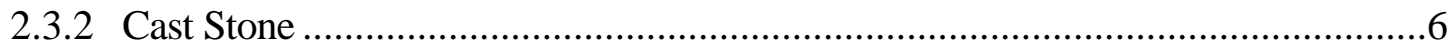

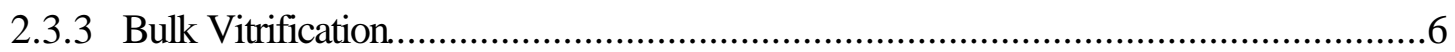

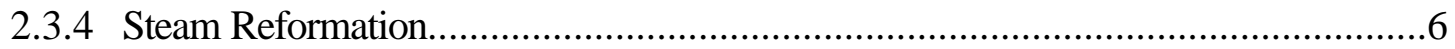

2.3.5 Computational Approach...............................................................................6

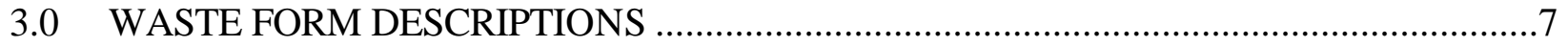

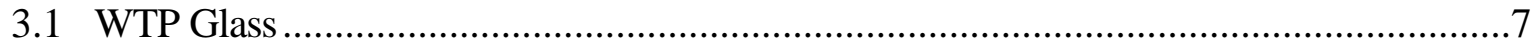

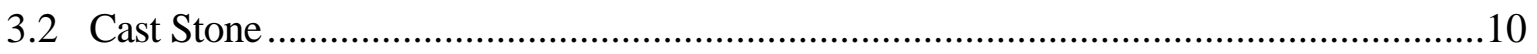

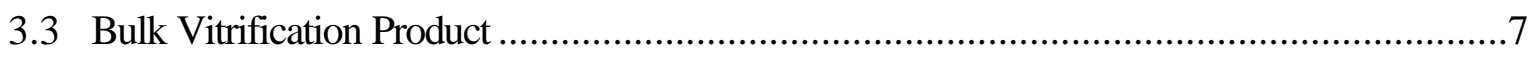

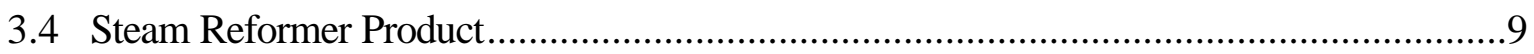

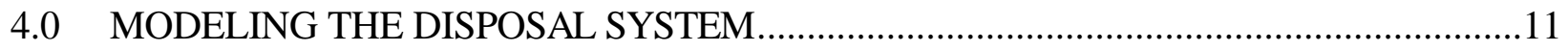

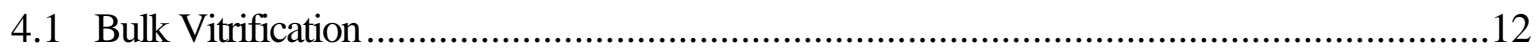

4.1.1 Froth Layer..............................................................................................13

4.1.2 Quartz Insulating Layer....................................................................................

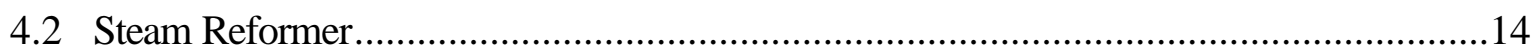

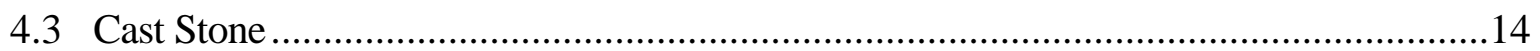

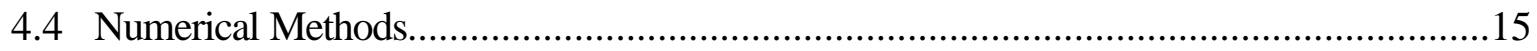

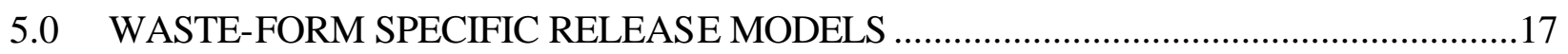

5.1 Glass Corrosion Process ...........................................................................................

5.1.1 Rate Law for Hydrolysis and Dissolution..........................................................18

5.1.2 Secondary Phase Formation..........................................................................19

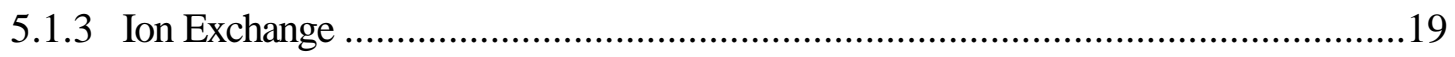

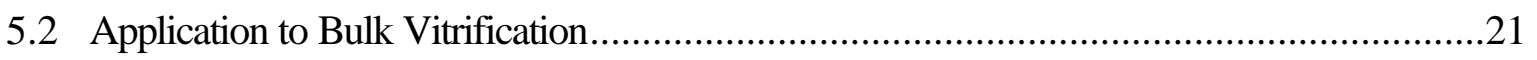

5.3 Contaminant Release Rate for Steam Reformed LAW ……………….........................22

5.4 Contaminant Release Rate for Cast Stone ……..........................................................22

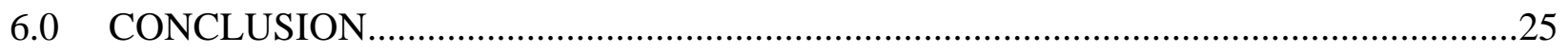

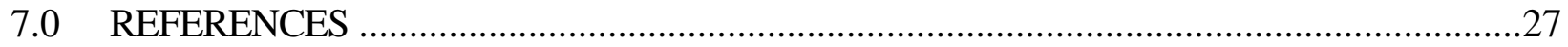




\section{Figures}

Figure 1. IDF Trench Conceptual Model................................................................................ 5

Figure 2. Picture of Edge Piece Broken Off From Near the East Electrode of Large Scale Test \#2 .... 8

Figure 3. Picture of Froth Layer Sample From Large Scale Test \#2 ............................................ 9

Figure 4. Modeling Strategy for Assessing ILAW Disposal System Impacts ............................... 12

Figure 5. Sodium-H Exchange Rate Versus Reciprocal Temperature for LAWABP1 Glass ............. 20

\section{Tables}

Table 1. Composition (Mass\%) of LAW Glasses........................................................................ 7

Table 2. Composition (Mass\%) of Typical BV Glass ….................................................... 8 


\subsection{Introduction}

The Hanford Site in southeastern Washington State has been used extensively to produce nuclear materials for the U.S. defense arsenal by the U.S. Department of Energy (DOE) and its predecessors, the U.S. Atomic Energy Commission and the U.S. Energy Research and Development Administration. A large inventory of radioactive and mixed waste has accumulated in 177 buried single- and doubleshell tanks. The DOE is proceeding with plans to permanently dispose of this waste (ECOLOGY et al., 1989). Liquid waste recovered from the tanks will be pretreated in a Waste Treatment Plant (WTP) to separate the low-activity fraction from the high-level and transuranic wastes. The small volume of highlevel immobilized waste and the much larger volume of immobilized low-activity waste (ILAW) will be disposed of in different locations. The high-level waste (HLW) will be stored on the Hanford Site until being sent to a federal geologic repository. The ILAW will be placed in a near-surface disposal system on the Hanford Site. The LAW at Hanford is among the largest volumes of waste within the DOE complex and is one of the largest inventories of long-lived radionuclides planned for disposal in a lowlevel waste facility. Principal contaminants of concern in LAW are ${ }^{99} \mathrm{Tc},{ }^{129} \mathrm{I}, \mathrm{U}, \mathrm{Cr}$, and nitrate/nitrite (MANN et al., 2003).

A significant portion of the LAW will be converted into glass at the WTP with a conventional slurryfed Joule-heated ceramic melter. In 2002, the DOE began implementation of an accelerated cleanup plan for the Hanford Site designed to shorten the overall cleanup by at least 35 years. A key element of the accelerated cleanup plan is a strategic initiative for acceleration of tank waste treatment by increasing the capacity of the WTP and using supplemental technologies for waste treatment and immobilization for as much as $70 \%$ of the LAW (DOE, 2002). Three supplemental treatment options for immobilization of low-activity tank waste are being evaluated: 1) bulk vitrification (BV), 2) cementation or the cast stone (CS) process, and 3) steam reformation (SR). Bulk vitrification (AMEC Earth \& Environmental, Inc.) is a modification to the in situ vitrification (ISV) process developed for remediation of buried wastes and contaminant plumes in soils (TIXIER et al., 1991; LUEY and SEILER, 1995). An in-container vitrification process is envisioned in which LAW and glass forming chemicals are melted by electrical resistance heating. The BV waste and container are then disposed in a LAW burial ground. Grout or cementitious waste forms are produced by mixing together low-activity liquid waste with a mixture of cement-forming chemicals (such as Portland cement, fly ash, clays and blast furnace slag) to form a slurry that solidifies by hydration reactions. The present concept differs from prior work on grout waste forms conducted at Hanford (KINCAID et al., 1994) in that grout would be mixed and then solidified in mild steel containers, a containerized grout process (Fluor Federal Services, Inc.). The steam reformation process is based on the THOR Treatment Technologies, LLC fluidized bed process. Briefly, the process operates by introducing high sodium nitrate content tank wastes into a moderate temperature $\left(650-800^{\circ} \mathrm{C}\right)$ fluidized bed vessel operating under vacuum. The tank waste is reacted with carbon and iron-based reductants to convert nitrates and nitrites directly to nitrogen gas. Radionuclides, alkali metals, sulfate, chloride, fluoride, and non-volatile heavy metals in the waste stream are reacted with clay (kaolinite) or other inorganic materials to produce a polycrystalline mineral product. Additional details on the process can be found in the report by Jantzen (2002) or at the THOR website (www.thortt.com). 
Each supplemental treatment technology will be evaluated against pre-determined criteria in areas such as safety, environmental protection, schedule, cost, operability, and interfaces. The initial technology selection is scheduled to be completed by October 30, 2003. The environmental protection aspects of any ILAW forms are evaluated through a performance assessment, which is a document that describes the long-term impacts of the disposal facility on public health and environmental resources. Results from a performance assessment conducted for disposed WTP low-activity waste glass have been published (MANN et al., 2001). A major conclusion from this study is that release rate of radionuclides from the WTP glass by reaction with water is one of the key parameters that determines the impacts of the disposal action and is the most uncertain. Unless the time required to release the immobilized contaminants from the supplemental waste form(s) is significantly shorter than for WTP glass, the release rate from the supplemental forms will similarly determine overall impacts from the disposal facility.

A general approach for the evaluation of materials behavior in a disposal site has been developed that outlines logical steps to validate and confirm the corrosion behavior of materials whose life expectancies must greatly exceed the length of time over which experimental data can be obtained (ASTM 1991). These steps include determining the likely range of environmental factors in the disposal system, identifying and characterizing materials that are likely to be present in the disposal system, performing tests under site-relevant conditions to determine important alteration processes for those materials, developing models for key alteration processes, and performing tests that accelerate those processes. The ASTM protocol also recommends tests to confirm the corrosion model and to utilize information provided by analog materials or systems. Many steps in this approach relevant to waste form behavior in general have been completed in studies conducted for deep geologic disposal systems and can be directly applied to the Hanford system. For example, the processes that control silicate-glass corrosion are relatively well understood, and rate expressions have been developed and tested. However, for the other supplemental waste forms being considered here, less fundamental scientific work has been conducted with respect to evaluating long-term corrosion behavior. This includes identifying (or confirming) the corrosion processes that will control the long-term release of radionuclides, measuring parameters needed to perform model calculations for performance assessment, and conducting accelerated and service condition tests to confirm and provide confidence in those calculations.

Consequently, the purpose of this document is to outline a risk assessment strategy that is acknowledged to be less rigorous and detailed than a performance assessment but of sufficient technical credibility to support a decision-making process for selection among bulk vitrification, cementation, and steam reformation technologies for treating Hanford LAW. The general technical strategy described in this report was developed by Pacific Northwest National Laboratory (PNNL) staff and follows similar methods that have been used to evaluate the long-term radionuclide release behavior of baseline WTP glasses (MCGRAIL et al., 2000a). However, it is not intended to serve as the technical basis for a testing program that is needed to complete a performance assessment for an Integrated Disposal Facility (IDF) containing these waste forms. We expect development of such a strategy will be pursued if one or more of the alternative ILAW forms is selected for further development. We begin the discussion of the technical strategy with a brief overview of the disposal system design and expected environmental conditions at the site. 


\subsection{Disposal System Description}

The Hanford Site is a $1450 \mathrm{~km}^{2}$ area of semi-arid land located in southeastern Washington state. Average annual precipitation is $16 \mathrm{~cm}$, with $44 \%$ of this total occurring during November, December, and January. Daytime high temperatures in summer can exceed $40^{\circ} \mathrm{C}$, while outbreaks of arctic air masses in winter can cause temperatures to drop below $-18^{\circ} \mathrm{C}$. Plans call for the disposal system to include a protective surface barrier with design elements to minimize root intrusion, animal intrusion, and water infiltration. The use of silt-loam soils when combined with a representative community of shrubsteppe vegetation has been shown to cause most precipitation falling on the region to be lost through evapotranspiration. Consequently, the disposal facility is to be located in relatively dry, unsaturated soil, and performance assessment models must be applicable to the specific physics and chemistry of this type of system.

\subsection{Water Infiltration}

Water flow in the near-surface unsaturated zone is transient because of intermittent precipitation events. Transient water flow begins when water enters at the ground surface and infiltrates downward into the soil column. One generally accepted conceptual model of natural recharge through the entire sediment profile follows. At some distance from the ground surface, transient effects will dampen out, and the downward flowing water will reach a steady infiltration rate. The distance at which steady infiltration occurs is sometimes referred to as the penetration depth (EAGLESON, 1978; SALVUCCI, 1993). Thus, the unsaturated zone essentially comprises two regions: an unsteady-flow region between the ground surface and penetration depth, and a steady-flow region between the penetration depth and the saturated zone water table. The steady flux in the lower unsaturated region is equal to the annual rate of ground-water recharge and therefore is composed of contributions not only from the most recent pulse, but from previous precipitation events as well.

The IDF will be situated below the penetration depth in the region of steady flow. The natural rate of moisture infiltration is approximately $4.2 \mathrm{~mm} / \mathrm{year}$ (FAYER et al., 1999). However, the natural rate of moisture infiltration cannot be relied upon because construction of the disposal system will destroy the natural soil-sediment profile and remove surface vegetation. Consequently, a protective surface barrier will be engineered with sediment layers and a capillary barrier to prevent or minimize infiltration. The design basis for the Hanford barrier (MYERS and DURANCEAU, 1994) specifies that less than 0.5 $\mathrm{mm} / \mathrm{year}$ will pass through the barrier for the first 1,000 years. Infiltration beyond the root zone is controlled at the soil/atmosphere interface where surface soils and sediments, and vegetation, interact with the climate. The frequency, duration, and magnitude of precipitation and runoff events determine the infiltration rate. Infiltration into the disposal facility will be controlled by the physics described above, the unsaturated hydraulic properties of the surface and subsurface barriers to infiltration, the vault and surrounding soil, and the matric and gravity potential gradients. 


\subsection{Facility Description}

The proposed location for the IDF is in the south-central part of the 200 East Area between existing office structures and the PUREX fuel reprocessing facility. The site is not near any existing or past waste disposal sites. A conceptual design has been described by Mann et al. (2003) and is shown in Figure 1. Loading of the WTP glass waste packages into the IDF trench is presently assumed to result in an overall packing fraction of waste packages of $40 \%$ by volume. The supplemental technology waste packages, which are boxes rather than cylinders, are assumed to result in approximately $60 \%$ packing fraction by volume. The remaining fill material into the trench is assumed to be backfill soil. Each cell in the IDF trench consists of a contiguous group of waste packages in a given layer.

The closure cap (surface barrier) is assumed to have the same relative thickness, materials, and slope as the modified RCRA subtitle $\mathrm{C}$ closure cap. Below the closure cap is a capillary break consisting of a $1 \mathrm{~m}$ thick sand layer immediately below the surface barrier, followed by a gravel layer between the top of the trench and the sand layer. The function of the capillary break is to divert moisture penetrating the closure cap around the waste packages. The sand plus gravel layers together have an apex over the center of the trench and have a $2 \%$ slope towards the long edge of each trench. The RCRA subtitle $\mathrm{C}$ closure cap and the capillary break have a combined thickness of greater than $5 \mathrm{~m}$ per NRC requirements (10 CFR 61).

Backfilled soil is included around and on top of the waste containers in the facility. The soil was included in these concepts 1) for structural support, 2) to wick moisture away from the waste containers, and 3 ) to provide radiation shielding for the facility workers. The waste packages are to be located approximately $15 \mathrm{~m}$ below the top of the surface barrier. At this depth, the ambient temperature is approximately $15^{\circ} \mathrm{C}$, and temperature fluctuations are less than $2^{\circ} \mathrm{C}$. The LAW processed through the WTP generates only a small amount of heat from radioactive decay (MCGRAIL and BACON, 1998), so the disposal system can be treated adequately as an isothermal system. Insufficient information on waste pre-treatment options for the supplemental waste forms is available to adequately assess whether the isothermal assumption is still valid for an IDF containing these waste forms. A heat-transfer analysis will need to be conducted after the initial technology selection.

\subsection{Waste Package Descriptions}

\subsubsection{Waste Treatment Plant Glass}

Canisters produced through the WTP are to be right circular cylinders (1.22 m diameter by $2.29 \mathrm{~m}$ tall), made of 304L stainless steel and at least $85 \%$ filled with LAW glass ( $2 \mathrm{~m}$ high). These waste packages are stacked 4 layers high maximum in the IDF trench. This corresponds to a maximum glass height of 8 meters. Stresses induced from differential rates of cooling are expected to induce stress fractures in the glass. Our baseline assumption is that available glass surface area is 10X greater than geometric surface area (PETERS and SLATE, 1981; FARNSWORTH et al., 1985). 


\section{East - West Cross-Section}

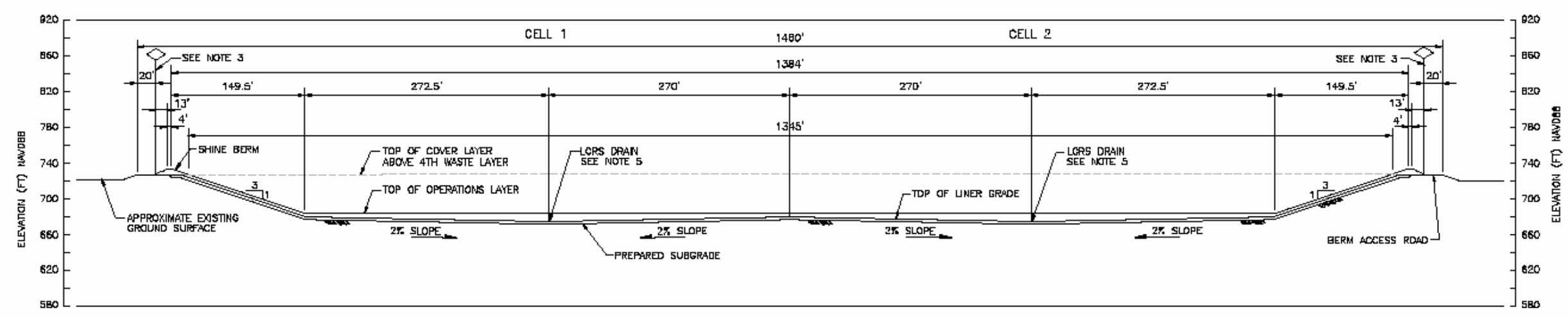

\section{North - South Cross Section}

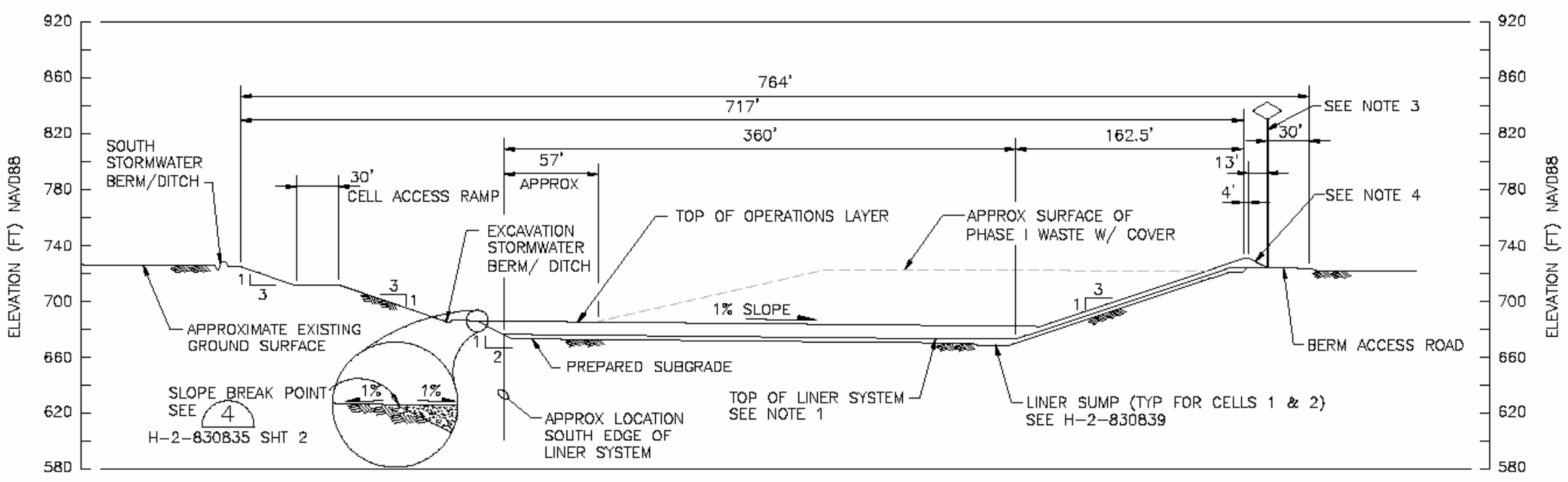

Figure 1. IDF Trench Conceptual Model 


\subsubsection{Cast Stone}

The vendor-recommended waste package design for the containerized cast stone waste form is a carbon steel container of about $12 \mathrm{~m}^{3}$ internal volume. The pre-conceptual design considers a box container configuration of $2.7 \mathrm{~m} \times 2.7 \mathrm{~m} \times 1.7 \mathrm{~m}(9 \mathrm{ft} \times 9 \mathrm{ft} \times 5.5 \mathrm{ft}){ }^{(\mathrm{a})}$ ILAW feed and cast stone reagents are mixed in batches that are poured into the containers for curing. Containers are specified to have less than $10 \%$ void space, which would include any shrinkage during the initial cement cure.

\subsubsection{Bulk Vitrification}

Waste packages for the BV process are planned to be rectangular boxes, $2.3 \mathrm{~m} \times 2.3 \mathrm{~m} \times 7.3 \mathrm{~m}$ ( $7.5 \mathrm{ft} \times 7.5 \mathrm{ft} \times 24 \mathrm{ft}$ ) and made of mild steel. A $15.2 \mathrm{~cm}$ (6 in) layer of quartz sand is placed on the bottom and four sides to act as insulation between the molten glass and steel during processing. The vitrified block will be in direct contact with the sand layer and some of the quartz grains are expected to be fully or partially entrained in glass. The vitrification process causes significant volume reduction; approximately $24.5 \mathrm{~m}^{3}$ of starting waste-soil-sand mix is specified to produce $10 \mathrm{~m}^{3}$ of glass product. The resulting void space in the top of the container is to be backfilled with clean soil and gypsum recycled from the off-gas treatment system. The vendor is also considering a modification to the process to incorporate twice as much final glass product in each package.

\subsubsection{Steam Reformation}

The waste package for SR LAW is specified as rectangular box $2.4 \mathrm{~m}$ x $2.6 \mathrm{~m}$ x $6.1 \mathrm{~m}(8 \mathrm{ft} \times 8.5 \mathrm{ft}$ x $20 \mathrm{ft}$ ) made of $304 \mathrm{~L}$ stainless steel. Because the SR process produces a granular product, the vendor specifies filling to $97 \%$ of the useable interior container volume.

\subsubsection{Computational Approach}

Because final waste package designs have not been selected, and because it was considered desirable to minimize possible performance variability based on somewhat arbitrary waste package geometry, each of the three waste forms will be treated with an identical waste package configuration, a $2.4 \mathrm{~m}$ x $2.4 \mathrm{~m}$ x $6.1 \mathrm{~m}(8 \mathrm{ft} \times 8 \mathrm{ft}$ x $20 \mathrm{ft})$ box. This approach also simplifies setup of a computational grid for modeling as it permits use of the same grid spacing and waste package orientation in simulations of all three waste forms, hence focusing the analysis on the relative performance of each waste form and not on packaging.

\footnotetext{
(a) The $90 \%$ design incorrectly specified a $9 \mathrm{~m}$ x $9 \mathrm{~m}$ x $5.5 \mathrm{~m}$ container. Personal communication, Jon Peschong (Columbia Energy, Inc.) to Phil Gauglitz (PNNL), August 18, 2003.
} 


\subsection{Waste Form Descriptions}

In this section we provide general descriptions of the compositions and characteristics of each ILAW form that is being considered for supplemental treatment. We begin with a description of the baseline WTP glass.

\subsection{WTP Glass}

Low activity waste (LAW) streams for the WTP are divided into three classifications or compositional envelopes:

Envelope A: This is the majority of the LAW. In pretreatment, entrained solids will be removed by ultrafiltration, and cesium will be removed by ion exchange.

Envelope B: This is the liquid portion separated from combined slurried Envelope B/D transfers (Envelope D is the solid high-level waste (HLW) fraction). Envelope B has the highest level of cesium. Cesium will be removed by ion exchange prior to vitrification. Chemically, this envelope is characterized by high contents of sulfate (as well as $\mathrm{Cl}, \mathrm{Cr}, \mathrm{F}$, and $\mathrm{PO}_{4}{ }^{3-}$ ), which limit waste loading.

Envelope C: This envelope contains higher concentrations of cesium, technetium, and organically complexed strontium and transuranic radionuclides. Sulfate also limits waste loading in this case. Pretreatment consists of cesium removal by ion-exchange and $\mathrm{Sr} / \mathrm{TRU}$ removal by $\mathrm{Sr} / \mathrm{Mn}$ precipitation.
Table 1. Composition (Mass\%) of LAW Glasses

\begin{tabular}{|c|c|c|}
\hline Oxide & $\underline{\text { LAWABP1 }}$ & $\underline{\text { LAWA44 }}$ \\
\hline $\mathrm{Al}_{2} \mathrm{O}_{3}$ & 10.00 & 6.20 \\
\hline $\mathrm{B}_{2} \mathrm{O}_{3}$ & 9.25 & 8.90 \\
\hline $\mathrm{CaO}$ & 0.00 & 1.99 \\
\hline $\mathrm{Cl}$ & 0.58 & 0.65 \\
\hline $\mathrm{Cr}_{2} \mathrm{O}_{3}$ & 0.02 & 0.02 \\
\hline $\mathrm{F}$ & 0.04 & 0.01 \\
\hline $\mathrm{Fe}_{2} \mathrm{O}_{3}$ & 2.50 & 6.98 \\
\hline $\mathrm{K}_{2} \mathrm{O}$ & 2.20 & 0.50 \\
\hline $\mathrm{La}_{2} \mathrm{O}_{3}$ & 2.00 & 0.00 \\
\hline $\mathrm{MgO}$ & 1.00 & 1.99 \\
\hline $\mathrm{Na}_{2} \mathrm{O}$ & 20.00 & 20.00 \\
\hline $\mathrm{P}_{2} \mathrm{O}_{5}$ & 0.08 & 0.03 \\
\hline $\mathrm{SiO}_{2}$ & 41.89 & 44.55 \\
\hline $\mathrm{SO}_{3}$ & 0.10 & 0.10 \\
\hline $\mathrm{TiO}_{2}$ & 2.49 & 1.99 \\
\hline $\mathrm{ZnO}$ & 2.60 & 2.96 \\
\hline $\mathrm{ZrO}_{2}$ & 5.25 & 2.99 \\
\hline
\end{tabular}

Retention of sulfur in the Envelope B and C glasses without the formation of undesirable molten salt phases during processing is the critical constraint on these glass formulations. Such phases are more corrosive, electrically conductive, and fluid than the glass melt, and have lower melting point. Glass formulations to be produced at the WTP continue to evolve as additional information is gathered about tank waste compositions, processing constraints, and long-term waste form performance. All WTP glasses considered to date are alkali borosilicates. The reference WTP glass used in the 2001 ILAW PA (MANN et al., 2001) was LAWABP1; its composition is given in Table 1. The current A-envelope reference glass formulation is LAWA44, which is also given in Table 1.

\subsection{Bulk Vitrification Product}

Bulk vitrification (AMEC Earth \& Environmental, Inc.) is a modification to the in situ vitrification (ISV) process developed for remediation of buried wastes and contaminant plumes in soils (TIXIER et 
al., 1991; LUEY and SEILER, 1995). An in-container vitrification process has been designed in which LAW, soil, and glass forming chemicals are mixed, dried, and then melted at about $1500^{\circ} \mathrm{C}$ by electrical resistance heating (KIM et al., 2003). Graphite flakes are added to the mix to form a conductive path for melt initiation. Current is supplied by two graphite electrodes imbedded in the batch. The high-temperature glass melt is kept insulated from the steel container by lining the container walls with a $15 \mathrm{~cm}$ (6 in) of Lane Mountain \#16 quartz sand. Gases generated during the process are vented to an offgas treatment system.

The target BV glass is quite similar to WTP glass; a typical glass composition is provided in Table 2. Major differences are that it is lower in $\mathrm{B}_{2} \mathrm{O}_{3}$ and considerably higher in $\mathrm{ZrO}_{2}$. Indeed, recent XRD analyses of $\mathrm{BV}$ glasses produced in full-scale tests have shown baddeleyite $\left(\mathrm{ZrO}_{2}\right)$ crystals in the product, suggesting that the melt is near solubility limits with respect to $\mathrm{ZrO}_{2}$.

During the vitrification process, partial dissolution of the insulating layer of quartz sand occurs into the $\mathrm{BV}$ melt. This tends to raise the $\mathrm{SiO}_{2}$ content of the final product glass from the target. Heating into the temperature range of the $\mathrm{BV}$ melt $\left(\approx 1500^{\circ} \mathrm{C}\right)$ also causes phase changes in the quartz sand; high-temperature, low-pressure $\mathrm{SiO}_{2}$ polymorphs identified in samples taken from large-scale tests of the process include several forms of tridymite and cristobalite. Consequently, five sides of the BV box contain a sequence of layers that generally progress from the outer edge towards the melt as follows:

$$
\alpha \text {-quartz } \rightarrow \text { Tridymite } \rightarrow \text { cristobalite } \rightarrow \text { glass melt }
$$

Figure 2 shows the layer structure observed along an edge broken off near the East electrode from large-scale test \#2 of the BV process. The yellow coloration was identified as zincite $(\mathrm{ZnO})$ that apparently formed from vaporization of a piece of galvanized steel flashing that was placed near the top of the melt.

Another important aspect of the BV process is the generation of a so-called "froth layer" on the top surface of the melt. The froth layer is analogous to the vesicular tops of basalt lava flows formed by gas bubbles trapped in the melt (REIDEL et al., 2002). A photo of froth-layer sample obtained from large-scale test \#2 of the BV process is shown in Figure 3 . The froth layer has higher porosity and hence available surface area for glass dissolution and contaminant release than the bulk of the melt.
Table 2. Composition (Mass\%) of Typical BV Glass

$\begin{array}{lr}\mathrm{Al}_{2} \mathrm{O}_{3} & 9.22 \% \\ \mathrm{~B}_{2} \mathrm{O}_{3} & 4.62 \% \\ \mathrm{CaO} & 2.69 \% \\ \mathrm{Cr}_{2} \mathrm{O}_{3} & 0.10 \% \\ \mathrm{Fe}_{2} \mathrm{O}_{3} & 4.00 \% \\ \mathrm{~K}_{2} \mathrm{O} & 1.93 \% \\ \mathrm{MgO} & 1.16 \% \\ \mathrm{Na}_{2} \mathrm{O} & 21.64 \% \\ \mathrm{P}_{2} \mathrm{O}_{5} & 0.48 \% \\ \mathrm{SO}_{3} & 0.51 \% \\ \mathrm{SiO}_{2} & 46.94 \% \\ \mathrm{TiO}_{2} & 0.64 \% \\ \mathrm{ZrO}_{2} & 6.06 \%\end{array}$

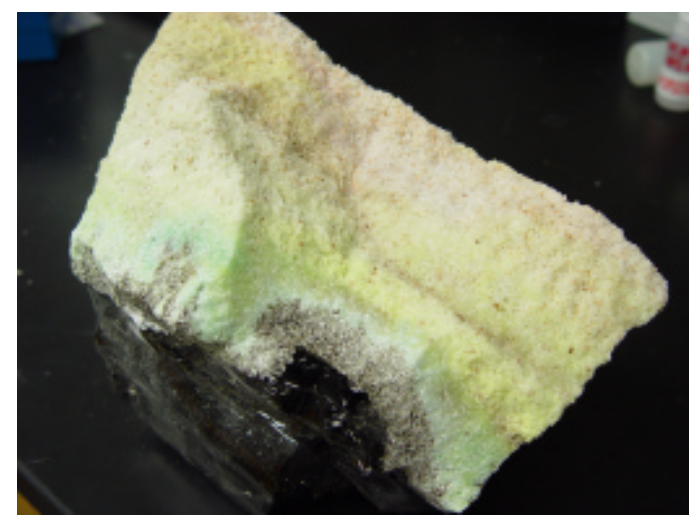

Figure 2. Picture of Edge Piece Broken Off From Near the East Electrode of Large Scale Test \#2 
Broken pieces of foam-layer glass obtained from an engineering-scale test (EST-01) of the BV process (KIM et al., 2003) were also analyzed. These pieces were originally located in proximity to a graphite electrode but their precise location was not recorded prior to removal from the glass block. A white substance was noted covering all or portions of the undersides (toward the melt) of several of these samples. X-ray diffraction and SEM analyses showed the substance to be a combination of several melt volatilization products, including $\mathrm{KReO}_{4}$ and Re metal. Rhenium was used as a non-radioactive chemical analog for Tc in the EST-01 test. The presence of a readily soluble alkali oxide of $\operatorname{Re}$ is

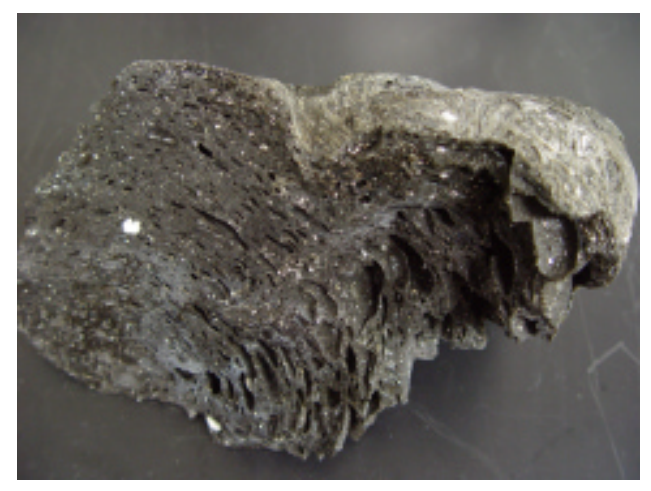

Figure 3. Picture of Froth Layer Sample From Large Scale Test \#2 important because if Tc forms a similar salt, it will act as an essentially instantaneous release sourceterm, once the mild steel waste package is breached, that must be considered. However, engineers from AMEC, Inc. believe that far less volatilization will occur at full scale because of the much lower electrode to melt surface area ratio. Initial visual observations of foam layer samples from large-scale test \#2 appear to corroborate this view. Additional discussion on quantification of Tc volatilization and condensation during the BV process is provided in Section 5.2.

\subsection{Steam Reformer Product}

The THOR ${ }^{\mathrm{TM}}$ FBSR process operates by introducing high sodium nitrate content tank wastes into a moderate temperature $\left(650-800^{\circ} \mathrm{C}\right)$ fluidized bed. The tank waste is reacted with carbon and ironbased reductants to convert nitrates and nitrites directly to nitrogen gas. Radionuclides, alkali metals, sulfate, chloride, fluoride, and non-volatile heavy metals in the waste stream are reacted with clay (kaolinite) or other inorganic materials to produce a polycrystalline mineral product. Additional details on the process can be found in the report by Jantzen (2002) or at the THOR Treatment Technologies, LLC website (www.thortt.com).

Extensive characterization and testing studies have been performed on a SR product manufactured in a 6-inch diameter, fluidized bed pilot plant at Hazen Research (Golden, Colorado) and the results documented by Jantzen (2002) and McGrail et al (2003b). The SR process produces a granular product with grain sizes ranging between $4 \mathrm{~mm}$ and $1 \mathrm{~mm}$ diameter. The primary minerals in the product examined by Jantzen (2002) and McGrail et al. (2003b) were nepheline $\left(\mathrm{NaAlSiO}_{4}\right)$ and nosean $\left[\mathrm{Na}_{8}\left(\mathrm{AlSiO}_{4}\right)_{6} \mathrm{SO}_{4}\right]$; small amounts of hematite, magnetite, and corundum were also detected. From testing data and independent mineral synthesis work (MATTIGOD et al., 2003), Rhenium [Re] (chemical analog for Tc) was inferred to be located principally in the nosean phase. Packing efficiency of the SR product in its container was specified by $\mathrm{THOR}^{\mathrm{TM}}$ at $70 \%$ pore space by volume but the sample examined by McGrail et al. packed to a total porosity of 65\%. Scanning electron microscopy of SR grains shows highly irregular surfaces and micropores in each grain that was confirmed by porosimetry measurements. Additional details on physical and chemical properties of the SR product that could impact its performance is provided in Section 5.3. 


\subsection{Cast Stone}

Production of cast stone is performed by mixing dry reagents with LAW feed (nominal $5 \mathrm{M}$ sodium) that has been concentrated to $10 \mathrm{M}$ sodium by evaporation. The dry reagents consist of 1) Portland cement, 2) fly ash, 3) blast furnace slag (BFS), and 4) ferrous sulfate monohydrate. This formulation is essentially equivalent to salt stone grout formulations used at the Savannah River site (LANGTON et al., 1988; LANGTON, 1989).

Hydration and set of the cast stone product begins upon mixing the concentrated LAW liquid waste with the dry reagents. Each component contributes to a complex set of chemical reactions that consume water, produce heat, and form calcium-silicate-hydrate (CSH) gel. A generalized reaction scheme is

$$
\begin{aligned}
& \mathrm{Ca}_{3} \mathrm{SiO}_{5}+3 \mathrm{H}_{2} \mathrm{O}=x \mathrm{CaH}_{2} \mathrm{SiO}_{4}(1-x) \mathrm{SiO}_{2}+(3-x) \mathrm{Ca}(\mathrm{OH})_{2} \\
& \mathrm{Ca}_{2} \mathrm{SiO}_{4}+2 \mathrm{H}_{2} \mathrm{O}=x \mathrm{CaH}_{2} \mathrm{SiO}_{4}(1-x) \mathrm{SiO}_{2}+(2-x) \mathrm{Ca}(\mathrm{OH})_{2}
\end{aligned}
$$

where $x$ is the $\mathrm{Ca} / \mathrm{Si}$ ratio of the $\mathrm{CSH}$ gel. The $\mathrm{CSH}$ can be considered a solid solution consisting of a non-ideal mixture of the end-member components $\mathrm{CaH}_{2} \mathrm{SiO}_{4}(\mathrm{~s})$ and $\mathrm{SiO}_{2}(\mathrm{~s})$ (RAHMAN et al., 1999). The calcium hydroxide produced from reactions (1) and (2) reacts with silica and calcium aluminates in reactions such as

$$
\begin{gathered}
\mathrm{Ca}_{4} \mathrm{Al}_{2} \mathrm{Fe}_{2} \mathrm{O}_{10}+4 \mathrm{Ca}(\mathrm{OH})_{2}+22 \mathrm{H}_{2} \mathrm{O}=\mathrm{Ca}_{8} \mathrm{Al}_{2} \mathrm{Fe}_{2} \mathrm{O}_{14} \cdot 26 \mathrm{H}_{2} \mathrm{O} \\
\mathrm{Ca}_{3} \mathrm{Al}_{2} \mathrm{O}_{6}+\mathrm{Ca}(\mathrm{OH})_{2}+12 \mathrm{H}_{2} \mathrm{O}=\mathrm{Ca}_{4} \mathrm{Al}_{2} \mathrm{O}_{7} \cdot 13 \mathrm{H}_{2} \mathrm{O} .
\end{gathered}
$$

Reactions 1-4 (along with many others) produce solid particles that continue to grow with time (PETERSON et al., 2002) and develop a macroscopic fine-scale pore structure thereby trapping and limiting the transport of contaminants contained within the cast stone matrix. Hydration of BFS initially proceeds much slower than Portland cement, but the products of hydration are similar in terms of chemical make-up, i.e. CSH. Hydration of BFS depends on the activation of the glass component by hydroxyl and alkali ions available from the Portland cement hydration. Activation of the glass is relatively slow and causes a delay in the hydration of slag, which is reflected in slower setting and lower early strength development compared to Portland cement. BFS hydration products are generally found to be more gel-like, as compared to cement, and tend to fill voids contributing denseness to the cement paste, increased strength, and enhanced durability.

For some radionuclides, solubility limits can be exceeded in the cement pore water causing precipitation that controls their pore water concentration (GLASSER, 1999). For ${ }^{99} \mathrm{Tc}$, this is highly unlikely under oxidizing conditions. However, the blast furnace slag and $\mathrm{FeSO}_{4} \cdot \mathrm{H}_{2} \mathrm{O}$ additives to the cast stone are reductants that have been shown to cause reduction of Tc(VII) to Tc(IV) in cements (GILLIAM et al., 1990; ALLEN et al., 1997). Tc(IV) is highly insoluble and would be expected to precipitate as $\mathrm{TcO}_{2} \cdot \mathrm{xH}_{2} \mathrm{O}$ or $\mathrm{TcS}_{2}$ in cast stone (ALLEN et al., 1997). However, the authors are unaware of any direct measurements of $\operatorname{Re}$ (or $\mathrm{Tc}$ ) oxidation state in cast stone samples produced to date. If the $\mathrm{Tc}$ in cast stone is reduced, remobilization would require oxidation or complexation of the Tc(IV) with organic compounds (i.e. EDTA, HEDTA) present in LAW tank waste that are known to remain in cement pore water (SMILLIE and GLASSER, 1999). Issues surrounding Tc oxidation and other ageing mechanisms that could impact cast stone performance are discussed further in Section 5.4. 


\subsection{Modeling the Disposal System}

The fundamental objective of a risk assessment is to estimate the radiation dose to a future population as a result of any release and transport of radionuclides from disposed waste forms to the unconfined aquifer located approximately $70 \mathrm{~m}$ below the disposal facility. Waste form performance is obviously one of the significant factors that impacts disposal system performance. Computer models are used to simulate the processes controlling the release and transport of radionuclides to the unconfined aquifer. The computer codes must perform three major simulation functions: 1) release of contaminants from the waste forms, 2) transport of those contaminants through the engineered system, and 3) transport through the vadose zone to the groundwater. Details regarding modeling release of contaminants from each waste form will be discussed in Section 5.0.

In 1998, the Hanford Low-Activity Waste Disposal Project selected a reactive transport code to calculate contaminant release rates from the engineered components of the disposal system (MCGRAIL and BACON, 1998). The Subsurface Transport Over Reactive Multiphases (STORM) code describes multi-component reactive transport in an isothermal, partially saturated, porous medium. The model includes chemical reactions between aqueous, gaseous, and solid phases. Reactions involving minerals are described through appropriate kinetic rate laws, along with a special option for treating irreversible reactions (such as glass corrosion). Homogeneous reactions within the aqueous phase are assumed to be reversible with their reaction rates controlled by transport and local equilibrium mass action relationships. Local equilibrium between a gas or gas mixture and the aqueous phase is treated through Henry's law. Solute transport includes contributions from advection, diffusion, dispersion, and radioactive decay. The effects of changes in porosity, and hence hydraulic conductivity, caused by mineral precipitation-dissolution and changes in water saturation caused by water consumption-production in chemical reactions can also be used to alter the fluid flow field during a simulation.

The STORM simulator described above plays a crucial but still singular role in a general computational methodology to evaluate disposal system performance. The approach used in the 2001 ILAW PA is to divide the problem into logical parts that correspond to computer simulation tools that are applied in different parts of the problem domain. Figure 4 illustrates the recommended overall computational strategy. The very-near-surface infiltration rate provides a key boundary condition for the remainder of the simulations. The coupled unsaturated flow, chemical reactions, and contaminant transport simulator (STORM) is applied from just below the root zone to some distance into the soil (probably several meters) below the floor of the disposal vault. This region is defined as the near field. Water exiting the region near the vault is expected to be of high ionic strength and $\mathrm{pH}$ and this plume will migrate down into the soil column for some distance until dispersion and chemical interactions with the sediment components attenuate it. Beyond this depth, the chemical composition of the migrating fluid will likely change very little. Consequently, it is possible to limit the domain over which computationally intensive reactive chemical transport simulations must be performed by switching to a chemically nonreactive vadose zone flow and transport simulation in the far-field domain, using codes such as VAM3D. The radionuclide flux exiting the vadose zone to the unconfined aquifer is computed with VAM3D (or other code) and is used as a boundary condition for the unconfined aquifer flow and transport simulator. The final step in the methodology is to compute the impacts, if any, from ingestion, inha- 
lation, and external radiation to humans who become exposed to the contaminants by withdrawing water from the aquifer and using it for drinking, farming, and other purposes.

The methodology outlined in Figure 4 is robust for conducting a performance assessment. Each simulation tool is based on basic principles of physics, chemistry, and thermodynamics. No a priori assumptions are made about the performance of the waste form or other components of the engineered and natural system. Consequently, changes in boundary conditions, such as infiltration rate, or scenarios, such as an assumed failure of the capillary break, can be quantitatively assessed in terms of their overall impacts on system performance.

In this risk assessment for supporting selection of supplemental treatment technologies, we wish to utilize the modeling strategy outlined in Figure 4 to the maximum extent practicable given the available time, staff, and funding constraints. We do not anticipate any significant issues in applying the same or similar computational methods for the far-field and aquifer domains. Consequently, application of STORM or more

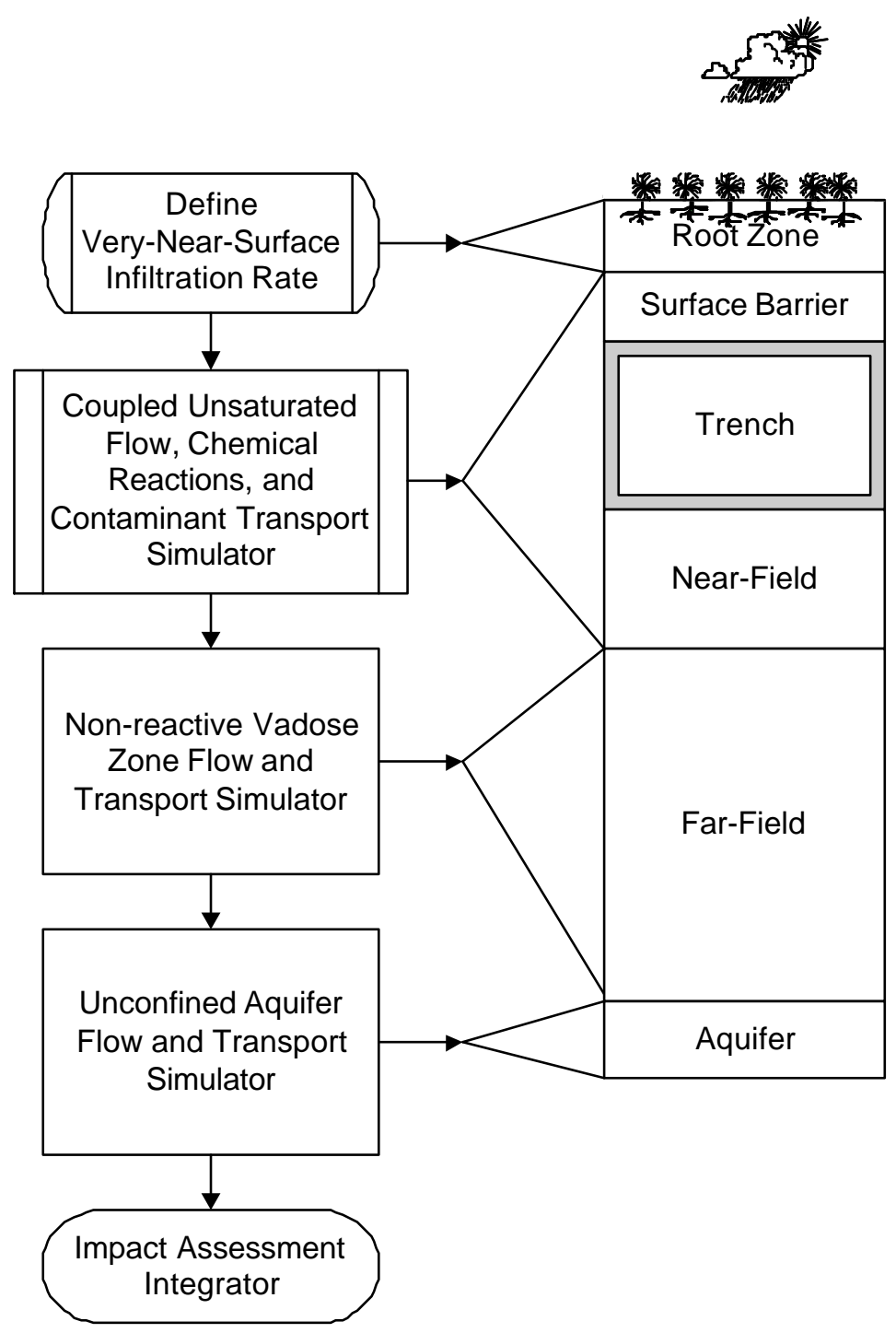

Figure 4. Modeling Strategy for Assessing ILAW Disposal System Impacts precisely availability of the necessary input data to run STORM for the near-field simulations for each supplemental waste form is the principal issue of concern. In the next section, we outline how we propose to model the near-field for each of the three supplemental waste forms.

\subsection{Bulk Vitrification}

As was discussed in Section 2.3.3, the composition of the BV product is similar to WTP glasses and so methods used to model WTP glasses and laboratory testing needed to derive the necessary input parameters (MCGRAIL et al., 2000a) for STORM can be used in a virtually identical manner. However, two significant differences between WTP glass waste packages and BV waste packages must be considered in the modeling: 1) physical and chemical properties of the "froth layer", and 2) interfaces of the quartz insulating layer and the bulk glass. 


\subsubsection{Froth Layer}

During the BV process, ${ }^{99} \mathrm{Tc}$ in the LAW is likely to get partitioned in three places, a soluble $\mathrm{KTcO}_{4}$ salt deposit in vesicles within the froth layer and perhaps coated on sand grains, in the glass matrix of the "froth", and in the bulk glass matrix. There is no generally applicable theory available to calculate the amount of volatilization that will occur during the BV process. AMEC, Inc. specifies 99.99\% retention of Tc but we could not locate specific data demonstrating how this value was obtained or the uncertainty in the estimate. Consequently, the amount of volatilization products in the froth layer (and sand) must be measured. Froth layer samples from a large-scale test of the BV process can be obtained by hand or with heavy machinery. The authors recommend that samples be taken from as many locations as practicable but particularly in proximity to the electrodes where temperatures are highest and thus where volatilization of $\mathrm{Tc}(\mathrm{Re})$ is expected to be the greatest. These samples can be soaked in water and the soluble Re (Tc) in the wash water analyzed. Total weight of the froth layer needs to be obtained at the same time so that a soluble Re (Tc) fraction per unit mass can be calculated.

The recommended washing procedure will only access open pore spaces in the froth layer samples. Consequently, physical property measurements on the froth layer are needed to correct the soluble Re (Tc) fraction to account for the presence of Re (Tc) in the closed porosity as well. It should also be noted that Re and Tc are known to behave differently in high-temperature processes (DARAB and SMITH, 1996). Technetium salts have lower vapor pressure and $\mathrm{Tc}$ is more easily reduced than $\mathrm{Re}$, both factors that are expected to reduce Tc volatilization as compared with Re. As no Tc data in the froth layer will be available from full-scale testing prior to selection, differences in Re and Tc volatilization will need to be considered from measurements conducted on engineering-scale melts (KIM et al., 2003).

The soluble Tc fraction estimate will be used directly as an input for risk assessment. In STORM, this is accomplished by putting the computed mass of $\mathrm{KTcO}_{4}$ per unit volume in a distinct "froth layer" lithological unit at the top of each waste package. If information is available on the amount of soluble Re (Tc) associated with the insulating layer sand is available, it should also be included in the calculation. The $\mathrm{KTcO}_{4}$ is assigned a large dissolution rate constant such that its release is essentially instantaneous at the start of a simulation. A solubility product for $\mathrm{KTcO}_{4}$ is available in the literature (NECK et al., 1998) but we do not expect sufficient K or Tc will be available to achieve saturation with respect to $\mathrm{KTcO}_{4}$.

In addition to a soluble Tc fraction, the higher porosity and surface area associated with the froth layer as compared with the bulk of the melt will impact its dissolution behavior. Several froth layer samples need to have their bulk density determined along with pore size distribution. Pore size distributions can be determined with x-ray microtomography (available at PNNL) of selected samples along with quantitative image analysis. A portion of each sample should be analyzed with XRD to identify any crystalline phases present. Composition differences between the froth layer glass and the bulk of the melt should also be examined. Again, differences in the physical, chemical, or dissolution kinetics properties of the froth layer glass can be handled in STORM by assigning these properties to a distinct lithological unit at the top of each waste package. 


\subsubsection{Quartz Insulating Layer}

The quartz insulating layer will be treated in STORM in essentially the same manner as the froth layer. That is, its physical, chemical, and mineralogical makeup should be determined and used to define a lithological unit for the sides and bottom of each waste package. Thermodynamic and kinetic rate law data are available in the literature for each of the $\mathrm{SiO}_{2}$ polymorphs that have been identified in this layer. Consequently, modeling this layer and any impacts it may have on the performance of the BV glass can be treated in a straightforward manner in STORM.

\subsection{Steam Reformer}

The SR process produces a polyphase crystalline ceramic waste form. However, the two major mineral phases in the product are nepheline and nosean, both silicate minerals. The reactive transport simulator is fully capable of treating the time and spatial dependence of the dissolution properties of these minerals provided the appropriate thermodynamic and kinetic data are available (see Section 5.3).

Assuming an appropriate kinetic rate equation for the key mineral phases in the SR product is completely parameterized, a disposal system performance analysis can be conducted for the SR product in a manner that is essentially equivalent to that for WTP glass. However, unlike glass, which ideally is a single phase material, a polycrystalline waste form like the SR product will have inherent differences in the dissolution rate of the mineral phases that comprise the product. Moreover, a rapidly dissolving phase could be present in the material but its dissolution rate may be limited by a slower-dissolving phase due to limited access to water. McGrail et al. (2003b) indirectly showed that nosean likely hosts Re in the SR product and so would likely host Tc as well. The key question is whether the major mineral phase in the SR product, nepheline, ultimately controls the dissolution of nosean and thus the release rate of Re (Tc) from the product. McGrail et al. (2003b) conducted post-test XRD analyses of SR samples after 28 days of Single Pass Flow Through (SPFT) testing at $90^{\circ} \mathrm{C}$. They found that diffraction peaks associated with nosean disappeared below detection limit while those of nepheline remained unaffected. ${ }^{(a)}$ Access to water does not appear to be a constraint that would limit the dissolution rate of nosean in the SR product. Consequently, the recommended modeling approach is to allow water access to all phases in the SR product and constrain the dissolution rate of each phase based on calculations via a kinetic rate equation similar to glass and not by a mass-transport constraint on water access.

\subsection{Cast Stone}

The framework for modeling the long-term performance of cementitious waste forms has been treated in a fundamentally different manner than for silicate-based glass and mineral forms. For the latter

\footnotetext{
${ }^{(a)}$ Disappearance of the nosean phase in the SR product during SPFT testing should not be construed as a negative outcome for the contaminant release characteristics of the SR product. The SPFT test is meant to characterize dissolution mechanisms and is not a realistic service condition test. Accelerated tests using the PUF system were conducted for months with the SR product at PNNL. No detectable change in the XRD pattern of the reacted solids was observed and release rates were found to be similar to glass (McGrail et al. (2003b).
} 
two, the rate-controlling mechanism is matrix hydrolysis in which chemical bonds are broken and contaminants released. With cementitious waste forms, a physical model of contaminant diffusion has been almost universally adopted. Empirical effective diffusion coefficients measured in short-term laboratory experiments are widely used to model the long-term performance of cementitious waste forms (ALBENESIUS, 2001). These diffusion measurements have changed little since the IAEA method was proposed by Hespe (1971) over 30 years ago. The effective diffusion coefficients measured for each contaminant are used for a diffusion-controlled transport analysis in the continuous pore network of the cast stone coupled with diffusive-advective transport in idealized fractures. These calculations will be performed with the multiphase flow and transport code STOMP (WHITE and OOSTROM, 2000). ${ }^{\text {(a) }}$ This approach is essentially equivalent to what has been performed for analysis of saltstone at the Savannah River site (COOK, 2000). Time-invariant effective diffusion coefficients measured in the ANS 16.1 laboratory test for selected radionuclides and chemical contaminants such as nitrate will be used. Additional details on the source-term model for cast stone are given in Section 5.4.

\subsection{Numerical Methods}

As it is currently configured, the STORM code represents a relatively complete model of the physical and reactive chemical transport processes that are required for simulating radionuclide release rates from the disposal system. However, the STORM code is fundamentally based on mass transport theory derived from principles of continuum mechanics. In reality, vitrified waste forms will be in the form of large glass blocks riddled with stress fractures. Berkowitz, Bear, and Braester (1988) suggested that solute transport in fractured media can be considered at a number of different scales. A near-field scale would include a few discrete fractures near the source. At a far-field scale, the fractured media could be treated as a continuum that is representative of an equivalent porous medium in which the repeating fractures behave as large pores. Their work focused on a contaminant source surrounded by a fractured porous medium. The fractured glass waste packages emplaced in a trench presents a different situation; the contaminants are already distributed within the glass matrix and are released as the glass dissolves. If stress fractures in the glass waste form are numerous and closely spaced, a continuum approach to modeling flow and transport through the waste packages is appropriate. However, because of the low water content in Hanford soils, only a few fractures may actually contain water. Under this scenario, the continuum assumptions can break down. Currently, the assumed fracture density in vitrified glass blocks has been sufficient to support the use of an equivalent porous medium approximation. Alternative modeling approaches, such as those based on lattice-Boltzmann (LB) theory, have been explored (MCGRAIL et al., 2000b) and could be utilized if required.

The SR product is a naturally granular material and so porous medium approaches are appropriate. An additional complication does occur because of dual porosity in the system. Agglomeration of individual mineral grains during the process produces granules that are microporous; packing of the SR granules into a waste package produces a packed bed with its own macroporosity. STORM has ca-

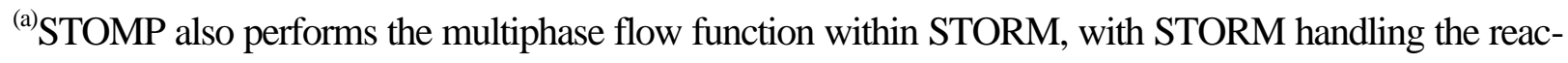
tive chemical transport function.
} 
pabilities for modeling such dual-porosity systems so the microstructure of the SR product can be adequately handled within the existing computation framework.

As cast stone is inherently a porous medium, there are no significant computational issues to address in terms of porous medium approximations. However, the cast stone blocks will be assumed to crack over time. It will be necessary to derive equivalent hydraulic properties for the fractured block by averaging over the cast stone block flow domain. The derived (upscaled) flow and transport properties should be used for simulations. 


\subsection{Waste-Form Specific Release Models}

The conceptual models that will be used to compute waste-form specific contaminant release rates are briefly reviewed below.

\subsection{Glass Corrosion Process}

A very large body of information is available on glass/water reaction processes. The interested reader should refer to the strategy document (MCGRAIL et al., 2000a) prepared for the ILAW disposal facility for detailed discussion of the various processes and conceptual models for these processes that are needed for silicate glasses. Only a brief overview will be provided here.

Glass forms ranging from simple binary and ternary silicate glasses to complex waste glasses with 30 or more components have been studied for over 40 years. Much of this work relevant to silicate waste glasses has been compiled and critically reviewed (BATES et al., 1994). A general understanding of the glass corrosion process in water has emerged that can be summarized as follows: upon initial contact by water, alkali is extracted by ion exchange in what is thought to be a diffusion-controlled process. Simultaneously, hydrolysis and dissolution of the glass network occurs. In unsaturated disposal systems where water content and flow rate are expected to be very low, the rate of ion exchange and dissolution decrease, but for different reasons. The ion-exchange rate slows in accordance with a diffusioncontrolled process as a reaction layer builds up on the glass over time. A reaction layer builds up as a result of silanol condensation reactions that reform $\mathrm{Si} \mathrm{O}$ bonds. The dissolution rate of the glass network slows because of the common ion effect, i.e., as the solution becomes more concentrated in dissolved glass components, the difference in chemical potential between the glass and aqueous phase decreases, which decreases the dissolution rate. The dissolution rate cannot become zero because silicate glasses are thermodynamically unstable in water.

As a solution in contact with a dissolving glass becomes more and more concentrated in glass components, solubility limits for alteration phases begin to be exceeded. Ultimately, the glass transforms into an assemblage of alteration products or minerals. The secondary phases that form from the glass/water reaction process are expected to depend principally on the composition of the glass and not on other components in the disposal system because the glass supplies the majority of the elements to the fluid from which the secondary phases precipitate. Glasses that are stable with respect to the formation of alteration products will maintain a slow but finite rate of network hydrolysis and dissolution indefinitely. Many existing natural glasses exhibit these characteristics, having withstood weathering over geologic time scales. Laboratory tests have generally reproduced the same types of alteration products that have been found on these natural glasses (GRAMBOW et al., 1986; LUO et al., 1997), confirming their longterm stability with respect to forming alteration phases. However, glasses that are unstable with respect to alteration product formation exhibit autocatalytic reactivity, i.e., a very rapid increase in dissolution rate that is limited only by the availability of water or the forward reaction rate of the glass, whichever is the rate limiting process. High-level waste glasses (VAN ISEGHAM and GRAMBOW, 1988) have exhibited this phenomenon and so have a few representative LAW glasses (MCGRAIL et al., 1998). Consequently, the laboratory testing program must ensure that the LAW glass(es) being produced by either 
the WTP or BV process fall into the former, stable category. If not, then the tests should provide guidance for modifying the glass composition into a region with known long-term stability.

A second mechanism important for LAW glasses because of their high Na content is ion exchange. Sheng, Luo, and Tang (1998) conducted static tests in a simulated groundwater and showed that alkali ion exchange was the dominant release mechanism over a large temperature range. Thus, glasses with lower alkali ion exchange rates are expected to exhibit better long-term performance in the disposal system. McGrail et al. (2001d) showed that rate of $\mathrm{Na}$ ion exchange for simple $\mathrm{Na}_{2} \mathrm{O}-\mathrm{Al}_{2} \mathrm{O}_{3}-\mathrm{SiO}_{2}$ glasses depends on 1) population density of non-bridging oxygen sites in the glass, 2) bond strength of $\mathrm{Na}$ atoms in $\mathrm{Si}-\mathrm{O}^{-} \mathrm{Na}^{+}$sites, and 3) mechanical stiffness (shear modulus) of the glass network. In addition, McGrail et al. (2001d) suggested that alkali ion exchange can also control the rate of glass matrix hydrolysis and dissolution under certain conditions, such as at low temperature and in solutions near saturation with respect to $\mathrm{SiO}_{2}(\mathrm{am})$. Recent work on an actual low-level waste glass buried in a Russian field test appears to support this hypothesis (MCGRAIL et al., 2003a).

Consequently, the major processes that must be modeled to evaluate long-term glass performance are: 1) matrix hydrolysis and dissolution, 2) secondary phase formation, and 3) alkali ion exchange. The conceptual models used for these processes are discussed next.

\subsubsection{Rate Law for Hydrolysis and Dissolution}

The corrosion of silicate glasses in water is represented with the chemical affinity rate law as a special type of irreversible dissolution reaction. The reaction is irreversible because the glass cannot be reformed by precipitation from aqueous solution. A conventional transition state kinetic rate equation can be used to compute the flux of any element $i$ released from the glass into the aqueous phase and is given by

$$
J_{i}^{a}=v_{i} \vec{k} \exp \left(\frac{-E_{a}}{\mathrm{RT}}\right)\left[1-\frac{Q}{K_{g}}\right] \prod_{j} a_{j}^{-\eta_{i}}, i=1,2, \ldots \mathrm{N} ; j=1,2, \ldots \mathrm{M}
$$

where

$a_{j}=$ activity of $j$ th aqueous species

$\vec{k}=$ intrinsic rate constant, $\mathrm{g} \mathrm{m}^{-2} \cdot \mathrm{s}^{-1}$

$\mathrm{E}_{\mathrm{a}}=$ activation energy, $\mathrm{J} / \mathrm{mol}$

$J_{i}^{a}=$ flux of element $i$ to the aqueous phase, $\mathrm{g} \mathrm{m}^{-2} \cdot \mathrm{s}^{-1}$

$K_{g}=$ equilibrium constant of rate controlling reaction

$\mathrm{M}=$ number of species directly affecting the rate

$\mathrm{N}=$ number of elements

$Q=$ ion-activity product of rate controlling reaction

$\mathrm{R}=$ gas constant, $8.314 \mathrm{~J} \mathrm{~mol}^{-1} \cdot \mathrm{K}^{-1}$

$\mathrm{T}$ = temperature, $\mathrm{K}$

$v_{i}=$ stoichiometric coefficient of element $i$ in the glass 
$\eta_{j}=$ stoichiometric coefficient for the $j$ th reactant species.

Equation (5) is a constitutive relationship that relates temperature and the composition of water contacting the glass to the corrosion rate. If it is assumed that $\mathrm{H}^{+}$is the only aqueous species that can directly influence the rate via the activity product term (BOURCIER et al., 1992), Equation (5) can be simplified to

$$
J_{i}^{a}=v_{i} \vec{k} \exp \left(-\frac{E_{a}}{\mathrm{RT}}\right)\left[1-\frac{Q}{K_{g}}\right] a_{\mathrm{H}^{+}}^{-\eta}
$$

where $a_{\mathrm{H}^{+}}$is the hydrogen ion activity. Because the temperature is assumed to be a known constant, and $v_{i}$ values are determined from the glass composition, application of Equation (6) for modeling glass corrosion in a disposal system requires the determination of four parameters; $\vec{k}, \mathrm{E}_{\mathrm{a}}, \eta, K_{g}$, and one variable, $Q$.

The ion activity product $(Q)$ is a variable and must be computed as a function of time and space for the disposal system (MCGRAIL and MAHONEY, 1995; BACON et al., 2000; MCGRAIL et al., 2001a). Computation of $Q$ is complex and depends on physical properties of the system, such as flow rate and glass surface area, and chemical properties, such as solubility products and the amounts and types of alteration products formed. Because transport and chemical processes interact, or more precisely are coupled, a special type of computational model, called a reactive chemical transport model, is required for simulations. This is the principal reason why the STORM reactive transport model was selected for the 2001 ILAW PA (MCGRAIL and BACON, 1998).

The parameters in Equation (6) can be most conveniently determined using the SPFT test method. Details regarding the SPFT method and techniques to derive $\mathrm{E}_{\mathrm{a}}, \eta, K_{g}$ from the test data can be found in (MCGRAIL et al., 2000a) and (MCGRAIL et al., 1997).

\subsubsection{Secondary Phase Formation}

As yet, there is no generally-accepted theory that allows one to compute from first principles a set of alteration phases that will form from a mixture of solutes. Thermodynamic principles (such as the Gibbs phase rule) simply determine which phases can form in a system and provide information on their relative stability. In glass-water systems, metastable phases are often the predominant secondary phases. Consequently, laboratory experiments remain the best means of identifying important alteration phases to consider in modeling. Any suitable laboratory test can be used to generate this information including vapor hydration tests, PUF tests, and PCT tests. Again, the phase identifications are simply used as inputs to STORM as part of its chemical reaction network. It does not mean that any particular phase will form in a simulation. That is strictly determined by the chemistry at each grid node in the simulation.

\subsubsection{Ion Exchange}

Although ion exchange has been largely ignored in the recent literature on the glass/water reactions, the process has been the subject of numerous early studies. In fact, the traditional idea of glass "leach- 
ing" involves the basic mechanism of ion exchange in which an $\mathrm{H}^{+}$or $\mathrm{H}_{3} \mathrm{O}^{+}$ion exchanges for an alkali ion $\left(\mathrm{M}^{+}\right)$in the glass, thereby generating a hydrated layer on the glass surface. The overall chemical reaction describing the process can be written as:

$$
\equiv \mathrm{Si}-\mathrm{O}-\mathrm{M}+\mathrm{H}^{+} \rightarrow \equiv \mathrm{Si}-\mathrm{OH}+\mathrm{M}^{+}
$$

or

$$
\equiv \mathrm{Si}-\mathrm{O}-\mathrm{M}+\mathrm{H}_{3} \mathrm{O}^{+} \rightarrow \equiv \mathrm{Si}-\mathrm{OH}+\mathrm{M}^{+}+\mathrm{H}_{2} \mathrm{O}
$$

McGrail et al. (2001b) used SPFT experiments to measure the Na ion-exchange rate for LAWABP1 glass by saturating the influent with respect to amorphous silica. As the concentration of dissolved silicon increased, sodium release rates became statistically faster than boron release rates. This divergence in rates at high silicon concentrations can be explained by the operation of two distinct mechanisms that release sodium to solution. The first mechanism is matrix dissolution and the second is alkali-H exchange. Under conditions of dilute solution compositions, the matrix dissolution mechanism dominates, so boron and sodium release rates are equal. In contrast, as silicon is added to solution, matrix dissolution rates are suppressed yet alkali-H exchange is unaffected and becomes dominant.

McGrail et al. (2001c) calculated sodium exchange rates by subtracting the normalized boron rate from the sodium release rate and then making the proper conversion to moles of sodium per unit area per time. Exchange rates for the four temperatures investigated are plotted with respect to temperature on Figure 5. The activation energy for the Na ion-exchange reaction for LAWABP1 glass is $52.7 \mathrm{~kJ} \mathrm{~mol}^{-1}$. The activation energy is similar to the value of $47.3 \mathrm{~kJ} \mathrm{~mol}^{-1}$ reported by Pederson (1987) for $\mathrm{Na}^{+}-\mathrm{H}^{+}$exchange in sodium silicate glass.

The experiments of McGrail et al. (2001c) show a constant rate of alkali ion exchange at a given temperature and $\mathrm{pH}$. Experiments to determine whether the ion exchange rate also varies

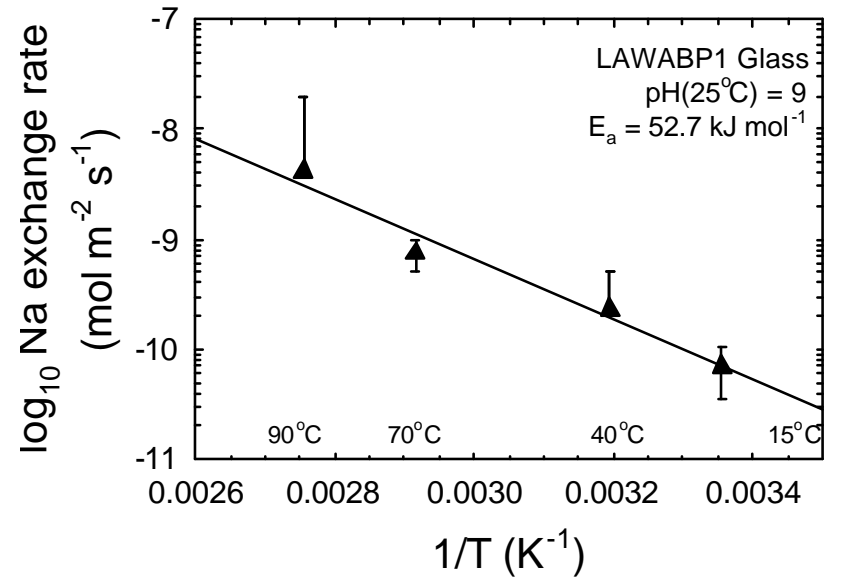

Figure 5. Sodium-H Exchange Rate Versus Reciprocal Temperature for LAWABP1 Glass. The slope of the line through the data indicate an activation energy of $52.7 \mathrm{~kJ} \mathrm{~mol}^{-1}$.

as a function of solution $\mathrm{pH}$ have not been performed. Assuming no $\mathrm{pH}$ dependence for the ionexchange rate, a rate law for the process can be completely parameterized. The exchange reaction is modeled using

$$
\text { Glass } \cdots \mathrm{Na}+\mathrm{H}^{+} \stackrel{r_{x}}{\longrightarrow} \text { Glass } \cdots \mathrm{H}+\mathrm{Na}^{+} .
$$

The computer model must keep track of the amount of hydrated glass formed via reaction (9). The hydrated glass can then be dissolved following the identical rate law used for the parent glass. 


\subsection{Application to Bulk Vitrification}

The methodology outlined above for modeling the long-term dissolution behavior of silicate glasses is applicable to BV glasses. However, as was noted in Section 4.1.1, a unique aspect of the BV process is the likely presence of water-soluble melt volatilization products in the vesicular glass at the top of the melt. We recommended in Section 4.1.1 methods to determine the amount of soluble Tc that should be used as an input to the BV calculation.

Because of the higher porosity and surface area associated with the foam layer as compared with the bulk of the melt, it is also important to characterize the dissolution behavior of the glass in this layer to determine if significant differences exist between the foam-layer glass and the bulk of the melt. Samples of foam-layer glass obtained from the EST-01 test had significant amounts of quartz sand adhering to the surface and embedded in the interior of the glass. Prior to testing these samples, we recommend a separation process to reduce the amount of quartz in the sample to the extent practicable. The removal of quartz (or at least quantifying the amount present) is important because it: 1) reduces the amount of glass per gram of sample and so introduces error in the calculation of glass $S / \mathrm{V}$ ratio for testing, 2) alters the rate of Si release to the aqueous solution and thereby may impact glass performance, and 3) could affect alteration phase formation, especially in accelerated tests. Laboratory experimentation showed that most of the quartz can be removed using a mixture of physical and mechanical separation processes that will consist of surface scraping, crushing, sieving, and hand removal of quartz grains from the glass specimen under a microscope. However, even the most careful sample preparation was unable to remove all the quartz as it was still readily detected with XRD analysis. Consequently, it must be expected that some amount of quartz will remain in even the most carefully prepared samples of foam-layer glass. Consequently, quantification of the amount of quartz in samples of foam-layer glass subjected to testing is mandatory. The internal standard method can be used to quantify the percentage of quartz in the glass sample (SYNDER and BISH, 1989). This method is a widely used in mineralogy and has been shown to be effective in quantifying the amount of quartz and cristobalite in bentonite clay (CARTER et al., 1987).

Once quantification of the amount of quartz in a foam-layer sample has been performed, a correction factor can be applied in calculating the glass $\mathrm{S} / \mathrm{V}$ ratio. Silicon release rates measured in SPFT tests can also be corrected by subtracting the quartz contribution, which can be readily calculated from literature data (DOVE and CRERAR, 1990; ANBEEK et al., 1994; DOVE, 1994).

Because of the prior work done on LAW glasses at Hanford, the authors have considerable confidence in the conceptual model being used to evaluate long-term contaminant release rates from BV. Glass formulation (KIM et al., 2003) has been performed using performance guidelines and testing methods established for WTP glasses. Impacts associated with the special features of the BV process, volatilized salts, froth layer, and fused silica polymorph/glass interfaces can all be handled with the existing computational framework. However, it must be recognized that a significant degree of uncertainty will exist with respect to the specific physical and chemical properties measured for BV. Adequate and accurate quantification of the amount of $\mathrm{KTcO}_{4}$ (or other soluble Tc salts) and the impacts of processing conditions and waste composition on variability of volatilization remain significant uncertainties. No data will be available from more advanced testing methods, such as the PUF test, to fully evaluate the long-term corrosion behavior of BV glasses in hydraulically unsaturated environments. Changes in the 
BV process, such as increasing the volume of vitrified waste per box, are being considered that will have undocumented impacts on the glass product. These uncertainties must be acknowledged and assessed during the selection process.

\subsection{Contaminant Release Rate for Steam Reformed LAW}

In STORM simulations, silicate minerals present in the soil are already modeled using the same kinetic rate equation (6) used for ILAW glass. Consequently, extension of the present model for the SR product is straightforward. The parameters $\vec{k}, \mathrm{E}_{\mathrm{a}}, \eta$, and $K$ need to be determined for both mineral phases present in SR. McGrail et al. (2003b) were able to extract kinetic rate constants and the $\mathrm{pH}$ power law coefficient $(\eta)$ from their SPFT experiments for both the nepheline and nosean components. Equilibrium constants $(K)$ are available for nepheline but not for nosean. However, a good theoretical model is available to calculate $K$ for zeolites such as nosean (MATTIGOD and MCGRAIL, 1999). The only missing parameter, therefore, is the activation energy $\left(E_{a}\right)$. Unfortunately, McGrail et al. (2003b) only conducted experiments at one temperature $\left(90^{\circ} \mathrm{C}\right)$, so $E_{a}$ cannot be determined from this dataset alone. However, additional temperature-dependent SPFT experiments are in progress at PNNL so all the parameters necessary to apply Equation (6) will be available for the SR product.

Although the authors believe the conceptual model for contaminant release from SR product is adequate, the reader should be aware that extremely limited information is available from which long-term performance will be assessed. Only a single vendor supplied product has been subjected to detailed characterization and testing, and this product was made with a less than full-scale fluidized bed reactor and with waste simulant. The authors have no means of assessing how representative the evaluated material is with respect to product produced with real tank waste. Variability in the mineral phase assemblages produced could have a major impact on SR product performance when dealing with the highly

variable waste streams at Hanford. Finally, the authors have no means of assessing the veracity of our hypothesis regarding the structural incorporation of Tc into the nosean phase. While this hypothesis is reasonable in our opinion, the presence of organic complexants in real tank waste, along with numerous competing anionic groups, could impact Tc incorporation into nosean and introduces considerable uncertainty into the analysis. These uncertainties must be considered during the selection process.

\subsection{Contaminant Release Rate for Cast Stone}

As was discussed in Section 4.3, contaminant release from cast stone will be evaluated outside the framework of STORM and will be performed using a simpler diffusive-advective transport model. Effective diffusion coefficients for each contaminant will be supplied by the cast stone vendor along with saturated hydraulic properties. Because we anticipate very low hydraulic conductivities for the cast stone, the release rate is expected to be predominately diffusion-controlled. The temporal signature for a diffusion-controlled process is typically a high initial mass flux that declines with the square-root of time. However, the grout blocks will be assumed to crack over time. The effect of cracking considered in a previous Hanford grout PA was to increase the saturated hydraulic conductivity (KINCAID et al., 1994) by 2 to 4 orders of magnitude. Diffusivity, porosity, and unsaturated hydraulic conductivity were 
assumed to be unaffected by cracking (KINCAID et al., 1994). These assumptions will alter the temporal signature from a purely $\sqrt{t}$ dependence at very long times in the simulations.

The principal issue to be addressed in this document is whether the proposed modeling approach introduces bias in the calculation for or against one waste form or the other. The authors in no way believe that selection of the simpler diffusion model for cast stone introduces a bias against cast stone. The selected model is appropriate for the physics of contaminant release from an inherently porous medium like cast stone. However, the authors are far less confident in the reverse question. That is, does selection of the simpler diffusion model introduce a bias in favor of cast stone? The authors do not believe that sufficient data is available on the product to form a scientifically credible answer. At the present time, it is only possible to identify important issues raised in prior studies that might affect the longterm performance of cast stone.

Although it is well-known that cementitious solids evolve from highly caustic calcium aluminosilicate amorphous gels to neutral more crystalline oxides, calcium carbonate, clays, and zeolites over hundreds to a few thousand years (BERNER, 1988; CRISCENTI and SERNE, 1990; CRISCENTI et al., 1996), reliable data on the fate of trace contaminants chemically or physically bound in cementitious solids during the aging or weathering process is very scarce. Moreover, the standard ANSI 16.1 test method for determining the release of contaminants from cement waste forms relies on freshly prepared test specimens (generally aged or cured for 28 days to allow solidification and strength development) and the testing then lasts in general for only 90 days, although a few tests have been performed out to several years (SERNE, 1990; SERNE et al., 1992). Still, aging effects, such as carbonation of Portland cement and blended cement-blast furnace slag, have been shown to increase release rates of $\mathrm{Cd}, \mathrm{Ni}, \mathrm{Pb}$, and Hg (BONEN and SARKAR, 1995) and Cr (MACIAS et al., 1997). However, in other tests, release rates of some of the same metals have been reduced after carbonation (Lange et al., 1997 and Hartmann et al., 1999). The mechanism(s) giving rise to these disparate observations though remain poorly understood (GLASSER, 1999). Whether or not chemical reactions associated with aging of cast stone would positively or negatively impact its long-term performance is unknown and would need to be investigated if cast stone is selected. Some useful cement characterization techniques that could be used to help improve our understanding of cement/cast stone/grout aging mechanisms are discussed by Klich et al., (1999a; 1999b; 2002). These characterization techniques, laboratory tests similar to the SPFT, PCT, and PUF methods discussed for ILAW waste glass, and studies targeted at acquiring thermodynamic and kinetic data for the important hydration reactions in cast stone could be used to obtain the required input parameters to the STORM code and thus put the cast stone release conceptual model on an equivalent basis with glass and/or steam reformed LAW.

It is also important to remember that reductants have been introduced in cast stone that have been demonstrated to lower the rates of Tc release in short-term laboratory tests with saltstone (GILLIAM et al., 1990; ALLEN et al., 1997). Technetium release rates are expected to be significantly lower than would be the case in absence of reductant. For example, $\mathrm{NO}_{3}{ }^{-}$is not reduced by $\mathrm{BFS}$ or $\mathrm{FeSO}_{4} \cdot \mathrm{H}_{2} \mathrm{O}$ in cast stone and its diffusion coefficient is about $100 \mathrm{X}$ greater than ${ }^{99} \mathrm{Tc}$ based on preliminary laboratory test data. However, if the reducing properties of the cast stone were to remain effective over the time frame of interest in a risk assessment (thousands of years), or if the Tc(IV) can be shown to be incorporated into the crystalline structure of one or more of the cement phases, use of the lower effective 
diffusion coefficients measured in short-term ANS 16.1 experiments would be appropriate for modeling long-term Tc release rates from cast stone. Unfortunately, maintenance of reducing conditions in cast stone pore water over these time frames, especially in a vadose zone environment, has not been demonstrated. Modeling calculations performed by Smith and Walton (1993) and direct measurements conducted by (ALLEN et al., 1997) and Shuh et al. (2000) suggest otherwise. Path lengths in containerized grout are much shorter than for very large blocks considered in prior studies at Hanford (KINCAID et al., 1995). Thus oxygen may penetrate to significant depths in the cast stone blocks over the time frame of interest. Finally, cracks in the cast stone blocks are not expected to fill with water in a vadose zone environment. Cracks, therefore, represent a short-circuit pathway for gaseous oxygen diffusion into the interior of the cast stone. For all these reasons, the authors are concerned about use of effective diffusion coefficients for Tc measured in very short-term laboratory tests with cast stone. These uncertainties will need to be carefully evaluated during the selection process.

A final consideration with respect to modeling cast stone is that time constraints prior to selection and the past practice precedent were the principal reasons why the effective diffusion coefficient approach was selected for modeling cast stone performance in this initial work. However, there is no fundamental scientific reason that empirical diffusion coefficients for each contaminant must be used to model cement waste form performance. Cementitious waste forms, such as cast stone, are inherently a porous medium and so diffusion, advection, and chemical reactions within its pores can all be treated within the framework of reactive transport theory (STEEFEL and LICHTNER, 1998). In fact, STORM has been used to model uranium and ${ }^{14} \mathrm{C}$ release from a grout disposal facility in Italy (BACON et al., 2002; BUCK et al., 2002). The chemical aging reactions and contaminant transport in cementitious forms are inherently coupled and so a reactive transport approach is well-suited for modeling long-term degradation and contaminant release from cast stone. Changes in hydraulic properties of the cast stone due to aging reactions could be handled through several available constitutive models built into STORM (FREEDMAN et al., 2003). Consequently, the authors are optimistic about the future of modeling longterm cementitious waste form behavior, especially with the establishment of a rigorous overall computational framework to guide the necessary data collection activities on the product. 


\subsection{Conclusion}

An overall strategy for evaluating the long-term performance of three waste forms being considered for supplemental treatment of low-activity waste at Hanford has been presented. The same computational framework used to conduct the 2001 ILAW performance assessment will be used for all three waste forms. Cast stone will be modeled with a diffusion-advection transport model and bulk vitrified glass and steam reformed LAW will be modeled with a reactive chemical transport simulator. The recommended laboratory testing to support the supplemental LAW form selection includes single-pass flow-through (SPFT), product consistency (PCT), and vapor hydration tests for glass, SPFT and PCT tests for steam reformed LAW forms, and ANS 16.1 tests for cast stone. These and potentially other laboratory tests would be needed for more detailed studies to support further evaluation should one or more of these waste form technologies be selected. 


\subsection{References}

Albenesius, E. L. 2001. Computer Modeling of Saltstone Landfills by Intera Environmental Consultants. DPST-83-529, Savannah River Site, Aiken, South Carolina.

Allen, P. G., G. S. Siemering, D. K. Shuh, J. J. Bucher, N. M. Edelstein, C. A. Langton, S. B. Clark, T. Reich, and M. A. Denecke. 1997. "Technetium Speciation in Cement Waste Forms Determined by X-ray Absorption Fine Structure Spectroscopy." Radiochim. Acta 76:77-86.

Anbeek, C., N. Vanbreemen, E. L. Meijer, and L. Vanderplas. 1994. "The Dissolution of Naturally Weathered Feldspar and Quartz." Geochim. Cosmochim. Acta 58(21):4601-4613.

Bacon, D. H., B. P. McGrail, V. L. Freedman, G. Ventura, P. Risoluti, and K. M. Krupka. 2002. "Performance Assessment of Low-Level Waste Disposal Facilities Using Coupled Unsaturated Flow and Reactive Transport Simulators." Mat. Res. Soc. Symp. Proc. 713:267-274.

Bacon, D. H., M. D. White, and B. P. McGrail. 2000. Subsurface Transport Over Reactive Multiphases (STORM): A General, Coupled Nonisothermal Multiphase Flow, Reactive Transport, and Porous Medium Alteration Simulator, Version 2, User's Guide. PNNL-13108, Pacific Northwest National Laboratory, Richland, Washington.

Bates, J. K., C. R. Bradley, E. C. Buck, J. C. Cunnane, W. L. Ebert, X. Feng, J. J. Mazer, D. J. Wronkiewicz, J. Sproull, W. L. Bourcier, B. P. McGrail, and M. K. Altenhofen. 1994. High-Level Waste Borosilicate Glass: A Compendium of Corrosion Characteristics. DOE-EM-0177, U.S. Department of Energy, Washington D.C.

Berkowitz, B., J. Bear, and C. Braester. 1988. "Continuum Models for Contaminant Transport in Fractured Porous Formations." Water Resour. Res. 24(8):1225-1236.

Berner, U. R. 1988. "Modeling the Incongruent Dissolution of Hydrated Cement Minerals." Radiochim. Acta 44-5:387-393.

Bonen, D. and S. L. Sarkar. 1995. "The Effects of Simulated Environmental Attack on Immobilization of Heavy-Metals Doped in Cement-Based Materials." J. Hazard. Mater. 40(3):321-335.

Bourcier, W. L., H. C. Weed, S. N. Nguyen, J. K. Nielsen, L. Morgan, L. Newton, and K. G.

Knauss. 1992. "Solution Compositional Effects on the Dissolution Kinetics of Borosilicate Glass." Proceedings of the Seventh Annual Water-Rock Interaction Conference, pp. 81-84.

Buck, J. W., B. P. McGrail, D. H. Bacon, V. L. Freedman, P. Ciabotti, and B. L. Hoopes. 2002. Modeling Methodology for Preliminary Performance Assessment of Italian Low-Level Radioactive Waste Repository. PNWD-3176, Battelle Pacific Northwest Division, Richland, Washington.

Carter, J. R. H., T. Mark, and L. Di Carlo. 1987. "Quantitative Analysis of Quartz and Cristobalite in Bentonite Clay Based Products by X-ray Diffraction." Anal. Chem. 59(3):513-519.

Cook, J. R. 2000. Radiological Performance Assessment for the E-Area Vaults Disposal Facility. WSRC-RP-94-0218, Rev. 1, Savannah River Site, Aiken, South Carolina. 
Criscenti, L. J. and R. J. Serne. 1990. "Thermodynamic Modeling of Cement/Groundwater Interactions as a Tool for Long-Term Performance Assessment." Mat. Res. Soc. Symp. Proc. 176:81-90.

Criscenti, L. J., R. J. Serne, K. M. Krupka, and M. I. Wood. 1996. Predictive Calulations to Assess the Long-Term Effect of Cementitious Materials on the pH and Solubility of Uranium(VI) in a Shallow Land Disposal Environment. PNNL-11182, Pacific Northwest National Laboratory, Richland, Washington.

Darab, J. G. and P. A. Smith. 1996. "Chemistry of Technetium and Rhenium Species During LowLevel Radioactive Waste Vitrification." Chem. Mater. 8:1004-1021.

DOE. 2002. Performance Management Plan for the Accelerated Cleanup of the Hanford Site. DOE/RL-2002-47, Revision D, U.S. Department of Energy, Richland, Washington, URL= http://www.hanford.gov/docs/rl-2002-47/rl-2002-47.pdf.

Dove, P. M. 1994. "The Dissolution Kinetics of Quartz in Sodium Chloride Solutions at $25^{\circ} \mathrm{C}$ to 300C." Am. J. Sci. 294:665-712.

Dove, P. M. and D. A. Crerar. 1990. "Kinetics of Quartz Dissolution in Electrolyte Solutions Using a Hydrothermal Mixed Flow Reactor." Geochim. Cosmochim. Acta 54:955-969.

Eagleson, P. S. 1978. "Climate, Soil and Vegetation, A Simplified Model of Soil Moisture Movement in the Liquid Phase." Water Resour. Res. 14(5):722-730.

Ecology, EPA, and DOE. 1989. Hanford Facility Agreement and Consent Order, As Amended. Washington State Department of Ecology, U.S. Environmental Protection Agency, and U.S. Department of Energy, Olympia, Washington, URL= http://www.hanford.gov/tpa/tpahome.htm.

Farnsworth, R. K., M. K. W. Chan, and S. C. Slate. 1985. "The Effect of Radial Temperature Gradients on Glass Fracture in Simulated High-Level Waste Canisters." Mat. Res. Soc. Symp. Proc.

44:831-838.

Fayer, M. J., E. M. Murphy, J. L. Downs, F. O. Khan, C. W. Lindenmeier, and B. N. Bjornstad. 1999. Recharge Data Package for the Immobilized Low-Activity Waste 2001 Performance Assessment. PNNL-13033, Pacific Northwest National Laboratory, Richland, Washington.

Freedman, V. L., K. P. Saripalli, and P. D. Meyer. 2003. "Influence of Mineral Precipitation and Dissolution on Hydrologic Properties of Porous Media in Static and Dynamic Systems." Appl. Geochem. 18(4):589-606.

Gilliam, T. M., R. D. Spence, W. D. Bostick, and J. L. Shoemaker. 1990. "Solidification Stabilization of Technetium in Cement-Based Grouts." J. Hazard. Mater. 24(2-3):189-197.

Glasser, F. P. 1999. "The Solubility Limited Source Term for Cement - Conditioned Wastes: A Status Report." Mat. Res. Soc. Symp. Proc. 556:1225-1236.

Grambow, B. E., H. P. Hermansson, I. K. Björner, H. Christensen, and L. Werme. 1986. Reaction of Nuclear Waste Glass with Slowly Flowing Solutions. In Advances in Ceramics, Vol. 20 (ed. D. E. Clark, W. B. White, and A. J. Machiels), pp. 465-474. American Ceramic Society, Westerville, Ohio. 
Hespe, E. D. 1971. Leach Testing of Immobilized Radioactive Waste Solids: A Proposal for a Standard Method. In Atomic Energy Review, Vol. 9, pp. 195-207. International Atomic Energy Agency, Vienna, Austria.

Jantzen, C. M. 2002. Engineering Study of the Hanford Low Activity Waste (LAW) Steam Reforming Process. WSRC-TR-2002-00317, Rev. 0, Westinghouse Savannah River Company, Aiken, South Carolina.

Kim, D.-S., J. D. Vienna, P. R. Hrma, M. J. Schweiger, J. Matyáš, J. V. Crum, D. E. Smith, G. J. Sevigny, W. C. Buchmiller, J. S. Tixier, V. J. Yeager, and K. B. Belew. 2003. Development and Testing of ICV Glasses for Hanford LAW. PNNL-14351, Pacific Northwest National Laboratory, Richland, Washington.

Kincaid, C. T., J. W. Shade, G. A. Whyatt, M. G. Piepho, K. Rhoads, J. A. Voogd, J. H. Westsik, Jr., K. A. Blanchard, and B. G. Lauzon. 1994. Performance Assessment of Grouted Double-Shell Tank Waste Disposal at Hanford. WHC-SD-WM-EE-004 Rev. 1, Westinghouse Hanford Company, Richland, Washington.

Kincaid, C. T., J. A. Voogd, J. W. Shade, J. H. Westsik, Jr., G. A. Whyatt, M. D. Freshley, M. G. Piepho, K. A. Blanchard, K. Rhoads, and B. G. Lauzon. 1995. Volume 1: Performance Assessment of Grouted Double-Shell Tank Waste Disposal at Hanford. WHC-SD-WM-EE-004, Pacific Northwest Laboratory and Westinghouse Hanford Company, Richland, Washington.

Klich, I., B. Batchelor, L. P. Wilding, and L. R. Drees. 1999a. "Mineralogical Alterations that Affect the Durability and Metals Containment of Aged Solidified and Stabilized Wastes." Cement and Concrete Res. 29(9):1433-1440.

Klich, I., L. P. Wilding, and L. R. Drees. 2002. "Trace Metal and Mineral Speciation of Remediated Wastes Using Electron Microscopy." Anal. Bioanal. Chem. 372(3):436-443.

Klich, I., L. P. Wilding, L. R. Drees, and E. R. Landa. 1999b. "Importance of Microscopy in Durability Studies of Solidified and Stabilized Contaminated Soils." Soil Sci. Soc. Am. J. 63(5):1274-1283.

Langton, C. A. 1989. Slag-Based Materials for Toxic Metal and Radioactive Waste Stabilization. DP-MS-87-95, Rev. 2, E. I. du Pont de Nemours \& Co., Savannah River Laboratory, Aiken, South Carolina.

Langton, C. A., S. B. Oblath, D. W. Pepper, and E. L. Wilhite. 1988. "Waste Salt Disposal at the Savannah River Plant." Chem. Eng. Comm. 66:189-199.

Luey, J. and D. K. Seiler. 1995. Application of In Situ Vitrification in the Soil Subsurface: Engineering-Scale Testing. PNL-10485, Pacific Northwest Laboratory, Richland, Washington.

Luo, J. S., W. L. Ebert, J. J. Mazer, and J. K. Bates. 1997. "Simulation of Natural Corrosion by Vapor Hydration Test: Seven-Year Results." Mat. Res. Soc. Symp. Proc. 465:157-163.

Macias, A., A. Kindness, and F. P. Glasser. 1997. "Impact of Carbon Dioxide on the Immobilization Potential of Cemented Wastes: Chromium." Cement and Concrete Res. 27(2):215-225.

Mann, F. M., R. J. Puigh, S. H. Finfrock, and R. Khaleel. 2003. Integrated Disposal Facility Risk Assessment. RPP-15834, Rev. 0, CH2M Hill Hanford Group, Inc., Richland, Washington. 
Mann, F. M., R. J. Puigh, II, S. H. Finfrock, E. J. Freeman, R. Khaleel, D. H. Bacon, M. P. Bergeron, B. P. McGrail, S. K. Wurstner, K. Burgard, W. R. Root, and P. E. LaMont. 2001. Hanford Immobilized Low-Activity Tank Waste Performance Assessment: 2001 Version. DOE/ORP-2000-24 Rev. 0, U.S. Department of Energy, Richland, Washington.

Mattigod, S. V. and B. P. McGrail. 1999. "Estimating the Free Energy of Formation of Zeolites Using the Polymer Model." Microporous and Mesoporous Materials 27:41-47.

Mattigod, S. V., B. P. McGrail, D. M. McCready, and K. E. Parker. 2003. "Synthesis and Structure of Perrhenate Sodalite." Chem. Mat. In press.

McGrail, B. P. and D. H. Bacon. 1998. Selection of a Computer Code for Hanford Low-Level Waste Engineered-System Performance Assessment. PNNL-10830 Rev. 1, Pacific Northwest National Laboratory, Richland, Washington.

McGrail, B. P., D. H. Bacon, W. L. Ebert, and K. P. Saripalli. 2000a. A Strategy to Conduct an Analysis of the Long-Term Performance of Low-Activity Waste Glass in a Shallow Subsurface Disposal System at Hanford. PNNL-11834 Rev. 1, Pacific Northwest National Laboratory, Richland, Washington.

McGrail, B. P., D. H. Bacon, J. P. Icenhower, F. M. Mann, R. J. Puigh, H. T. Schaef, and S. V. Mattigod. 2001a. "Near-Field Performance Assessment for a Low-Activity Waste Glass Disposal System: Laboratory Testing to Modeling Results." J. Nuc. Mat. 298(1-2):95-111.

McGrail, B. P., D. H. Bacon, P. D. Meyer, M. I. Ojovan, N. V. Ojovan, D. M. Strachan, and I. V. Startceva. 2003a. "New Developments in Field Studies of Low Activity Waste Glass Corrosion and Contaminant Transport." Mat. Res. Soc. Symp. Proc. In Press.

McGrail, B. P., W. L. Ebert, A. J. Bakel, and D. K. Peeler. 1997. "Measurement of Kinetic Rate Law Parameters on a Na-Ca-Al Borosilicate Glass for Low-Activity Waste." J. Nuc. Mat. 249:175-189.

McGrail, B. P., J. P. Icenhower, D. H. Bacon, H. T. Schaef, P. F. Martin, E. A. Rodriguez, and J. L. Steele. 2001b. Low-Activity Waste Glass Studies: FY2001 Summary Report. PNNL-13761, Pacific Northwest National Laboratory, Richland, Washington.

McGrail, B. P., J. P. Icenhower, P. F. Martin, D. R. Rector, H. T. Schaef, E. A. Rodriguez, and J. L. Steele. 2000b. Low-Activity Waste Glass Studies: FY2000 Summary Report. Pacific Northwest National Laboratory, Richland, Washington.

McGrail, B. P., J. P. Icenhower, P. F. Martin, H. T. Schaef, M. J. O'Hara, E. A. Rodriguez, and J. L. Steele. 2001c. Waste Form Release Data Package for the 2001 Immobilized Low-Activity Waste Performance Assessment. PNNL-13043 Rev. 2, Pacific Northwest National Laboratory, Richland, Washington.

McGrail, B. P., J. P. Icenhower, D. K. Shuh, P. Liu, J. G. Darab, D. R. Baer, S. Thevuthasen, V. Shutthanandan, M. H. Engelhard, C. H. Booth, and P. Nachimuthu. 2001d. "The Structure of $\mathrm{Na}_{2} \mathrm{O}-$ $\mathrm{Al}_{2} \mathrm{O}_{3}-\mathrm{SiO}_{2}$ Glass: Impact on Sodium Ion Exchange in $\mathrm{H}_{2} \mathrm{O}$ and $\mathrm{D}_{2} \mathrm{O}$." J. Non-Cryst. Solids 296(12):10-26. 
McGrail, B. P. and L. A. Mahoney. 1995. Selection of a Computer Code for Hanford Low-Level Waste Engineered-System Performance Assessment. PNL-10830, Pacific Northwest Laboratory, Richland, Washington.

McGrail, B. P., P. F. Martin, and C. W. Lindenmeier. 1998. Corrosion Testing of Low-Activity Waste Glasses: Fiscal Year 1998 Summary Report. PNNL-12014, Pacific Northwest National Laboratory, Richland, Washington.

McGrail, B. P., H. T. Schaef, P. F. Martin, D. H. Bacon, E. A. Rodriguez, D. E. McCready, and A. R. Primak. 2003b. Initial Suitability Evaluation of Steam-Reformed Low Activity Waste for Direct Land Disposal. WTP-RPT-097, Battelle, Pacific Northwest Division, Richland, Washington.

Myers, D. R. and D. A. Duranceau. 1994. Prototype Hanford Surface Barrier: Design Bases Document. BHI-007, Bechtel Hanford Company, Richland, Washington.

Neck, V., T. Könnecke, T. Fanghänel, and J. I. Kim. 1998. "Pitzer Parameters for the Pertechnetate Ion in the System $\mathrm{Na}^{+} / \mathrm{K}^{+} / \mathrm{Mg}^{2+} / \mathrm{Ca}^{2+} / \mathrm{Cr} / \mathrm{SO}_{4}{ }^{2-} / \mathrm{TcO}_{4}{ }^{-} / \mathrm{H}_{2} \mathrm{O}$ at $25^{\circ} \mathrm{C}$." J. Solution Chem. 27(2):107120.

Pederson, L. R. 1987. "Comparison of Sodium Leaching Rates From a $\mathrm{Na}_{2} \mathrm{O} \cdot 3 \mathrm{SiO}_{2}$ Glass in $\mathrm{H}_{2} \mathrm{O}$ and $\mathrm{D}_{2} \mathrm{O}$." Phys. Chem. Glasses 28(1):17-21.

Peters, R. D. and S. C. Slate. 1981. "Fracturing of Simulated High-Level Waste Canisters." Nuc. Eng. Design 67:425-445.

Peterson, V., B. Hunter, A. Ray, and L. P. Aldridge. 2002. "Rietveld Refinement of Neutron, Synchrotron and Combined Powder Diffraction Data of Cement Clinker." Appl. Phys. A-Mater. Sci. Process. 74:S1409-S1411.

Rahman, M. M., S. Nagasaki, and S. Tanaka. 1999. "A Model for Dissolution of CaO- $\mathrm{SiO}_{2}-\mathrm{H}_{2} \mathrm{O}$ Gel at $\mathrm{Ca} / \mathrm{Si}<1$ by Considering Disordered Structure." Mat. Res. Soc. Symp. Proc. 556:1237-1244.

Reidel, S. P., V. G. Johnson, and F. A. Spane. 2002. Natural Gas Storage in Basalt Aquifers of the Columbia Basin, Pacific Northwest USA: A Guide to Site Characterization. PNNL-13962, Pacific Northwest National Laboratory, Richland, Washington.

Salvucci, G. 1993. "An Approximate Solution for Steady Vertical Flux of Moisture Through an Unsaturated Homogeneous Soil." Water Resour. Res. 29(11):3749-3753.

Serne, R. J. 1990. "Grouted Waste Leach Tests: Pursuit of Mechanisms and Data for Long-Term Performance Assessment." Mat. Res. Soc. Symp. Proc. 176:91-99.

Serne, R. J., R. O. Lokken, and L. J. Criscenti. 1992. "Characterization of Grouted LLW to Support Performance Assessment." Waste Management 12:271-287.

Sheng, J. W., S. G. Luo, and B. L. Tang. 1998. "Temperature Effects on the Leaching Behavior of a High-level Waste Glass Form." Nuc. Tech. 123(3):296-303.

Shuh, D. K., N. M. Edelstein, C. J. Burns, W. W. Lukens, J. J. Bucher, M. G. Fickes, and B. L. Scott. 2000. Research Program to Investigate the Fundamental Chemistry of Technetium. EMSP- 
60296, Lawrence Berkeley National Laboratory, Berkeley, California, URL= http://emsp.em.doe.gov/EMSPprojects1996_2002/completed/60296.pdf.

Smillie, S. and F. P. Glasser. 1999. "Reaction of EDTA, Oxalic Acid and Citric Acid with Portland cement." Adv. Cem. Res. 11(2):97-101.

Smith, R. W. and J. C. Walton. 1993. "The Role of Oxygen Diffusion in the Release of Technetium From Reducing Cementitious Waste Forms." Mat. Res. Soc. Symp. Proc. 294:247-253.

Steefel, C. I. and P. C. Lichtner. 1998. "Multicomponent Reactive Transport in Discrete Fractures - II: Infiltration of Hyperalkaline Groundwater at Maqarin, Jordan, a Natural Analogue Site." J. Hydrol. 209(1-4):200-224.

Synder, R. L. and D. L. Bish. 1989. Quantitative Analysis. In Modern Powder Diffraction, Vol. 20 (ed. D. L. Bish and J. E. Post), pp. 101-144. Mineralogical Society of America.

Tixier, J. S., J. A. Stottlemyre, and M. T. Murphy. 1991. "Vitrified Underground Barriers." Waste Management '91, pp. 603-611.

Van Isegham, P. and B. Grambow. 1988. "The Long-Term Corrosion and Modelling of Two Simulated Belgian Reference High-Level Waste Glasses." Mat. Res. Soc. Symp. Proc. 112:631-639.

White, M. D. and M. Oostrom. 2000. STOMP - Subsurface Transport Over Multple Phases Version 2.0, Theory Guide. PNNL-12030, Pacific Northwest National Laboratory, Richland, Washington. 


\section{DISTRIBUTION}

No. of

Copies

OFFSITE

1 Westinghouse Savannah River

Company

P. O. Box 616

Aiken, SC 29802

Attn: G. G. Wicks

1 Sandia National Laboratories

1515 Eubank SE - MSIN 0748

Albuquerque, NM 87123-0748

Attn: R. D. Waters

\section{ONSITE}

$3 \quad$ U.S. Department of Energy

Office of River Protection

C. A. Babel, H6-60

P. E. Lamont, H6-60

B. M. Mauss, H6-60

13 CH2M HILL Hanford, Inc.

K. D. Boomer, R1-44

K. A. Gasper, H6-03

D. W. Hamilton, H6-03

M. E. Johnson, R1-44

W. A. Kitchen, H6-03

F. M. Mann, E6-35

R. W. Powell, H6-03 (5)

R. E. Raymond, H6-22

G. W. Reddick, Jr., R1-44
No. of

Copies

2 Fluor Federal Services, Inc.
R. J. Puigh, E6-17
R. Khaleel, E6-17

35 Pacific Northwest National

Laboratory

D. H. Bacon, K9-33

L. M. Bagaason, K6-28

T. M. Brouns, K9-69

P. A. Gauglitz, K6-28 (20)

B. P. McGrail, K6-81 (5)

E. M. Pierce, K6-81

H. T. Schaef, K6-81

R. J. Serne, P7-22

J. S. Tixier, K6-24

J. D. Vienna, K6-24

Information Release, K1-06 (2) 